\title{
Hydrogen Rearrangement in Molecular Ions of Alkyl Benzenes: Mechanism and Time Dependence of Hydrogen Migrations in Molecular Ions of 1,3-Diphenylpropane and Deuterated Analogues $\dagger$
}

Dietmar Kuck and Hans-Fr. Grützmacher $\ddagger$

Fakultät für Chemie der Universität Bielefeld, Universitätsstr., D 4800 Bielefeld 1, Germany

\begin{abstract}
Hydrogen migrations in the molecular ions of 1,3-diphenylpropane, preceding the fragmentations to $\left[\mathrm{C}_{7} \mathrm{H}_{7}\right]^{+}$ and $\left[\mathrm{C}_{7} \mathrm{H}_{8}\right]^{+}$ions, have been investigated by use of deuterated derivatives. By comparing the distribution of deuterium labels in the $\left[\mathrm{C}_{7}(\mathrm{H}, \mathrm{D})_{8}\right]^{+}$products from metastable molecular ions with the distribution patterns calculated for various exchange models, it is shown that the $H$ migrations occur by two processes linked by a common intermediate: (i) exchange between hydrogen isotopes at the $\gamma$-methylene group and at the ortho positions of the phenyl group: (ii) exchange between hydrogen isotopes at the ortho and ortho' positions in the intermediate. In these mechanisms the eight hydrogen isotopes at both benzylic positions and both the ortho and ortho' positions of 1;3-diphenylpropane participate in a mutual exchange. A statistical equipartition of the hydrogen isotopes at these eight positions is not reached in metastable molecular ions, however. The distribution pattern of $\left[C_{7}(H, D)_{8}\right]^{+}$ions from the deuterium labelled compounds as a function of the mean number $n$ of exchange cycles has been calculated according to this reaction model and compared with experimental results for unstable molecular ions, generated by $70 \mathrm{eV}$ and $12 \mathrm{eV}$ electrons, respectively, and metastable molecular ions. Good agreement is obtained for all compounds and $n=0.4-0.8$ for unstable molecular ions and $n=5-8$ for metastable ions. Therefore, the hydrogen exchange in the molecular ion of 1,3-diphenylpropane is a rather slow process. These results firmly establish the isomerization reaction involving the conversion of the molecular ion of 1,3-diphenylmethane to the intermediate and hence to the molecular ion of 7-(2-phenylethyl)-5-methylene cyclohexa-1,3-diene and preceding the fragmentations. The postulated intermediate is a true one which corresponds to a $\sigma$-complex type ion and which fragments to $\left[\mathrm{C}_{7} \mathrm{H}_{8}\right]^{+}$ions. Surprisingly, no isomerizations of the intermediate by hydrogen shifts within the protonated aromatic system ('ring walks') are observed.
\end{abstract}

\section{INTRODUCTION}

In a previous paper ${ }^{1}$ it has been shown that the rearrangement reaction of molecular ions of 1,3diphenylpropane (1) to $\left[\mathrm{C}_{7} \mathrm{H}_{8}\right]^{t}$ ions is probably a

$\dagger$ Mechanisms of Mass Spectrometric Fragmentation Reactions XIX Part XVIII. D. Kuck and H. F. Grützmacher, Org. Mass Spectrom. 13, $000(1978)$ two-step reaction involving the intermediate $[\mathrm{Z}]^{\ddagger}$. This was concluded from the effects of substituents at the aromatic rings on this fragmentation and from the results of appearance potential measurements and considerations of the energetics of these reactions. If $[Z]^{+}$is a true reaction intermediate with a real lifetime and not the transition state of the fragmentation, there should be an opportunity for $[\mathrm{Z}]^{+}$to return to $[1]^{+}$

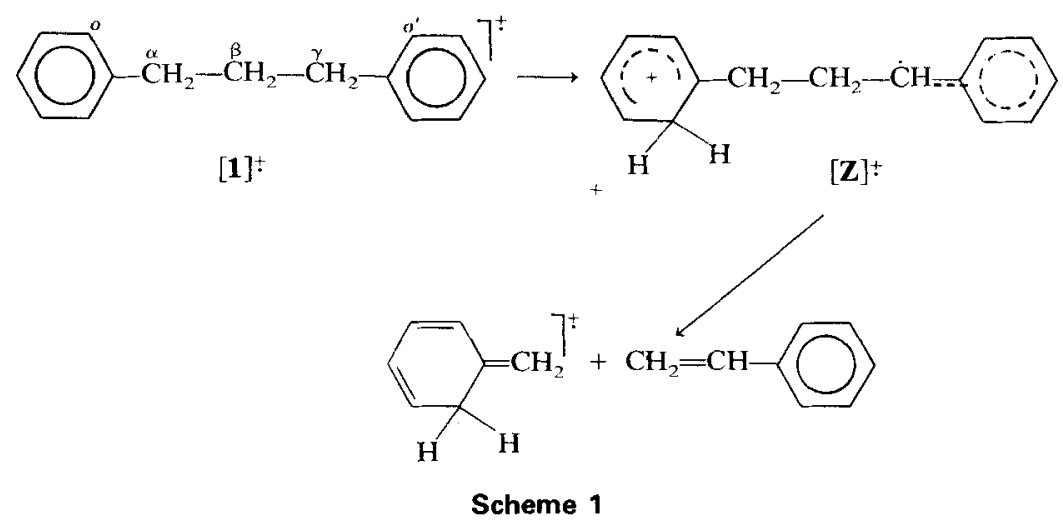

$¥$ Author to whom correspondence should be addressed.

(C) Heyden \& Son Ltd. 1978 
Table 1. Deuterium content and degree of deuteration ( $\delta$ ) of the labeled 1,3-diphenylpropanes (\%)

\begin{tabular}{|c|c|c|c|c|c|c|c|c|c|c|c|c|}
\hline & $d_{0}$ & $a_{1}$ & $d_{2}$ & $d_{3}$ & $d_{4}$ & $d_{5}$ & $d_{6}$ & $d_{7}$ & $d_{A}$ & $d_{9}$ & $d_{10}$ & $\delta$ \\
\hline $1 \mathrm{a}$ & - & 1.3 & 98.7 & - & - & - & - & - & - & - & - & 99.4 \\
\hline 16 & - & 0.4 & 2.8 & 96.8 & - & - & - & - & - & - & - & 98.8 \\
\hline Ic & - & - & - & 1.3 & 92.4 & 6.2 & - & - & - & - & - & 101.1 \\
\hline Id & 0.3 & 16.5 & 83.1 & - & - & - & - & - & - & - & - & 91.4 \\
\hline $1 e$ & - & - & 0.8 & 4.1 & 14.1 & 81.0 & - & - & - & - & - & 95.1 \\
\hline $1 f$ & - & - & - & $一$ & - & - & - & - & 4.5 & 95.5 & - & 99.5 \\
\hline $1 \mathrm{~g}$ & - & - & - & - & - & - & - & - & 6.6 & 88.1 & 4.1 & 98.5 \\
\hline
\end{tabular}

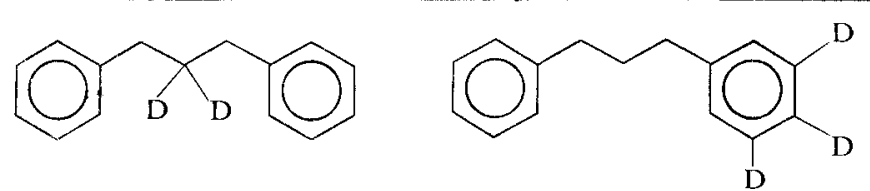

$1 \mathbf{a}$

$1 \mathbf{b}$

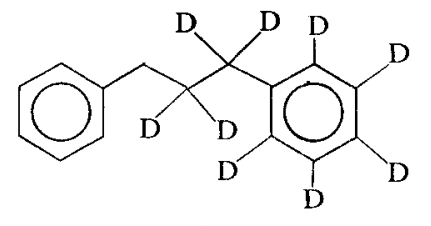

1f

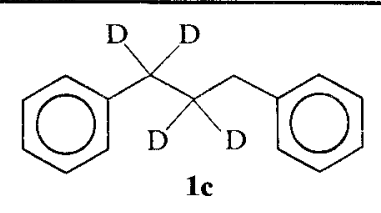

$1 \mathrm{c}$

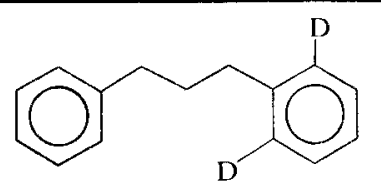

$1 d$<smiles>[2H]c1c([2H])c(CCCc2ccccc2)c(P)c(P)c1P</smiles>

1e<smiles>[2H]c1c([2H])c([2H])c(CC([2H])([2H])C([2H])([2H])c2ccccc2)c([2H])c1[2H]</smiles>

$1 \mathrm{~g}$ several times before fragmenting to the ions $\left[\mathrm{C}_{7} \mathrm{H}_{8}\right]^{+}$. In the case of appropriate deuterated derivatives of $[1]^{\ddagger}$ a reversible reaction $[1]^{+} \rightleftharpoons[\mathrm{Z}]^{ \pm}$will lead to positional changes between $H$ and $D$, which can be observed by a subsequent fragmentation to the ions $\left[\mathrm{C}_{7}(\mathrm{H}, \mathrm{D})_{8}\right]^{\dagger}$. As the observation of these hydrogen migrations would prove the two-step reaction mechanism for this well known mass spectrometric fragmentation of 1 and related alkylbenzenes, and at the same time shed some light on the chemical behaviour of protonated aromatic species related to $[\mathrm{Z}]^{+}$in the gas phase, the reaction has been investigated by the aid of the deuterated derivatives 1a-1g (Table 1).

\section{RESULTS}

Hydrogen migrations in $[\mathbf{1}]^{ \pm}$are investigated by means of the mass shifts of the non-fragmenting ' $C_{7}$ ' fragment ions $\left[\mathrm{C}_{7}(\mathrm{H}, \mathrm{D})_{7}\right]^{+}$and $\left[\mathrm{C}_{7}(\mathrm{H}, \mathrm{D})_{8}\right]^{+}$, the sum of which is approximately $50 \%$ of the total fragment ion current. ${ }^{1,2}$ The analysis of the $70 \mathrm{eV}$ spectra (Table 2) is complicated by the superposition of isobaric ions from both types of $\mathrm{C}_{7}$ ions. At $12 \mathrm{eV}$, in contrast to simple 1-phenylalkanes, ${ }^{3,4}$ only the rearrangement products $\left[\mathrm{C}_{7}(\mathrm{H}, \mathrm{D})_{8}\right]^{ \pm}$are observed (Table 3 ), due to their low appearance potential $\left(A\left[\mathrm{C}_{7} \mathrm{H}_{8}\right]^{+}(\mathbf{1})=9.7 \mathrm{eV}\right.$ cf. $\left.A\left[\mathrm{C}_{7} \mathrm{H}_{7}\right]_{(\mathbf{1})}^{+} \approx 11.6 \mathrm{eV}^{1}\right)$. Accordingly, the metastable molecular ions form $\left[\mathrm{C}_{7}(\mathrm{H}, \mathrm{D})_{8}\right]^{\dagger}$ almost exclusively, as far as the $\mathrm{C}_{7}$ ions are concerned (Table 4). In contrast to the $\mathrm{C}_{7}$ ions, the $\left[\mathrm{C}_{8} \mathrm{H}_{8}\right]^{+}(\mathrm{m} / \mathrm{e}$ 104) and $\left[\mathrm{C}_{8} \mathrm{H}_{9}\right]^{+}(\mathrm{m} / \mathrm{e} 105)$ ions are formed from low energy molecular ions simultaneously.

For clarity the analysis of the experimental data is restricted (except for 1a and 1b) to the low energy molecular ions fragmenting in the ion source (Table 3) and in the first field free region (Table 4). The results thus obtained can be applied easily to the analysis of the fragmentations of the highly excited molecular ions (Table 2).

Table 2. Relative abundances" of the $\mathrm{C}_{7}{ }^{+}$ions ${ }^{\mathrm{b}}$ from $[1]^{+}$and its deuterated analogues formed within the ion source $\left(\leqslant 10^{-6} s\right)$ after $70 \mathrm{eV}$ ionization

\begin{tabular}{|c|c|c|c|c|c|c|c|c|}
\hline$m / e$ & 1 & 1a & 1b & $1 \mathrm{c}$ & 1d & 10 & if & $1 g$ \\
\hline 89 & 1.1 & & 0.7 & 0.4 & 0.8 & 0.7 & 0.4 & \\
\hline 90 & 0.4 & 1.0 & 0.3 & 0.5 & 0.6 & 0.5 & 0.3 & 0.1 \\
\hline 91 & $36.1^{\circ}$ & $35.9^{\mathrm{c}}$ & $16.7^{c}$ & $11.5^{\mathrm{c}}$ & $17.0^{c}$ & $16.9^{\circ}$ & $9.7^{c}$ & 0.6 \\
\hline 92 & $62.4^{r}$ & $63.0^{r}$ & $33.4^{r}$ & 8.8 & $30.6^{r}$ & $26.3^{r}$ & 5.4 & 1.7 \\
\hline 93 & 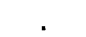 & . & 2.4 & $48.5^{\mathrm{c}, \mathrm{r}}$ & $28.4^{\mathrm{c}}$ & 6.4 & $21.5^{r}$ & $15.2^{\mathrm{c}}$ \\
\hline 94 & . & . & $15.0^{c}$ & $30.0^{r}$ & $22.6^{r}$ & 0.4 & 8.5 & $33.0^{r}$ \\
\hline 95 & . & . & $31.5^{r}$ & 0.3 & . & 5.0 & 2.4 & 4.0 \\
\hline 96 & . & . & . & . & . & $20.6^{c}$ & 1.6 & $11.3^{\mathrm{c}}$ \\
\hline 97 & . & . & . & . & . & $23.3^{r}$ & 8.3 & 6.0 \\
\hline 98 & . & . & . & . & . & . & $20.2^{c}$ & $27.8^{r}$ \\
\hline 99 & . & . & . & . & . & . & $21.7^{r}$ & 0.4 \\
\hline
\end{tabular}

${ }^{a}$ In $\% \Sigma\left[C_{7}\right]$; corrected for natural contributions of ${ }^{13} C_{1}$ and ${ }^{13} C_{2}$, but not for deficiency and/or excess of $D$ incorporation.

b The superscripts $(c)$ and $(r)$ indicate fragment ions that are expected qualitatively assuming no (additional) migrations of $H$ and $D$ before the cleavage reaction to $\left[C_{7}(H, D)_{7}\right]^{+}$and the rearrangement reaction to $\left[C_{7}(H, D)_{8}\right]^{+}$. 
Table 3. Relative abundances ${ }^{2}$ of the $\mathrm{C}_{7}{ }^{\dagger}$ ions $^{\mathrm{b}}$ from $[1]^{+}$and its deuterated analogues formed within the ion source $\left(\leqslant 10^{-6} \mathrm{~s}\right)$ after $12 \mathrm{eV}$ ionization

\begin{tabular}{ccccccccc}
\hline m/e & 1 & 1a & 1b & 1c & 1d & 1o & 1f & ig \\
91 & 2.5 & 3.4 & 2.4 & 0.8 & 1.0 &. & 0.4 &. \\
92 & $97.5^{r}$ & $96.6^{r}$ & $47.1^{r}$ & 8.8 & $26.3^{r}$ & $21.4^{r}$ & 0.7 & 0.1 \\
93 &. &. & 2.2 & $53.2^{r}$ & 43.8 & 24.4 & $14.1^{r}$ & 3.5 \\
94 &. &. & 2.8 & $37.2^{r}$ & $28.9^{r}$ & 5.7 & 18.2 & $39.8^{r}$ \\
95 &. &. & $45.6^{r}$ &. &. & 2.8 & 13.9 & 8.9 \\
96 &. &. &. &. &. & 20.2 & 6.8 & 3.5 \\
97 &. &. &. &. &. & $25.4^{r}$ & 14.8 & 8.3 \\
98 &. &. &. &. &. &. & 18.0 & $34.6^{r}$ \\
99 &. &. &. &. &. &. & $13.1^{r}$ & 1.2 \\
\hline
\end{tabular}

a,b See footnotes to Table 2.

The relative abundances of the $\mathrm{C}_{7}$ ions from [1a]t are identical to those from $[1]^{ \pm}$within experimental error in all energy regions, whereas the labelling in $[\mathbf{1 b}]^{+}$shifts both $50 \%$ of $\left[\mathrm{C}_{7} \mathrm{H}_{7}\right]^{+}$and $50 \%$ of $\left[\mathrm{C}_{7} \mathrm{H}_{8}\right]^{ \pm}$ by three $m / e$ units, indicating that the $\mathrm{H}$ atoms of the $\beta$-methylene group and at the meta and para positions are not involved in $\mathrm{H}$ migrations of the rearrangement reaction. Admittedly, the $C_{7}$ ions at $m / e 93$ and $m / e 94$ indicate migrations of the meta and para hydrogen atoms, occurring to a low extent at low excitation energies. However, this migration is too small ( $<5 \%$ for the metastable molecular ions) to invalidate the interpretation of the abundance distributions (patterns) of the $\mathrm{C}_{7}$ ions. All the other $\mathrm{H}$ atoms (i.e. the four benzylic and the four ortho positions) are involved in intramolecular $\mathbf{H}$ transfer reactions preceding the formation of $\left[\mathrm{C}_{7}(\mathrm{H}, \mathrm{D})_{8}\right]^{\dagger}$. This is obvious from the abundance distributions of the $\left[\mathrm{C}_{7}(\mathrm{H}, \mathrm{D})_{8}\right]^{+}$ions formed from the low energy molecular ions $[\mathbf{1 c}]^{\ddagger},[1 \mathbf{1 d}]^{\ddagger}$ and $[\mathbf{1 e}]^{\dagger}$ (Tables 3 and 4). For example, $[\mathbf{1 e}]^{+}$generates not only $\left[\mathrm{C}_{7} \mathrm{H}_{8}\right]^{+}(\mathrm{m} / \mathrm{e} 92)$ and $\left[\mathrm{C}_{7} \mathrm{H}_{3} \mathrm{D}_{5}\right]^{ \pm}(m / e$ 97) by transfer of a $\gamma-\mathrm{H}$ or $\alpha-\mathrm{H}$ atom, respectively, but to a much greater extent $\left[\mathrm{C}_{7}(\mathrm{H}, \mathrm{D})_{8}\right]^{+}$ions between these $m / e$ values.

It can be seen easily that exchange processes occu between the four benzylic hydrogen isotopes $(\gamma-\mathrm{H}$ and $\alpha-\mathrm{H})$ and the four ortho hydrogen isotopes $(o-\mathrm{H}$ and $\left.o^{\prime}-\mathrm{H}\right)$ respectively, increasing with increasing mean lifetime of the molecular ions. Moreover, it is obvious that these exchange processes occur repeatedly. The formation of $\left[\mathrm{C}_{7} \mathrm{H}_{6} \mathrm{D}_{2}\right]^{+}$ions $(m / e$ 94) with great abundance from the unlabelled benzyl groups of $[\mathbf{1 e}]^{t}$ and $[\mathbf{1 f}]^{ \pm}$proves qualitatively the predominant exchange of
$H(D)$ atoms between the two benzyl groups. Correspondingly, it follows from the abundance patterns of $[1 \mathrm{f}]^{\ddagger}$, being perdeuterated at one benzyl group, that up to three $\mathrm{D}$ atoms of the labelled benzyl group are exchanged for three $\mathrm{H}$ atoms of the unlabelled ones (Tables 3 and $4, m / e 99$ to $m / e 96$ ).

These results show qualitatively that the exchange reactions between aliphatic and aromatic $\mathrm{H}$ atoms are much more important in the molecular ions of $1,3-$ diphenylpropane (1) than those of simple arylalkanes. ${ }^{3}$

The following quantitative analysis of the abundance patterns of the $\left[\mathrm{C}_{7}(\mathrm{H}, \mathrm{D})_{8}\right]^{+}$ions from $[\mathbf{1 c}]^{+}$to $[\mathbf{1 g}]^{t}$ gives a more detailed insight into the mechanism of the $\mathrm{H}$ exchange reactions in $[\mathbf{1}]^{ \pm}$. For that purpose hypothetical abundance patterns have been calculated for a number of exchange models assuming complete equilibration of the $\mathbf{H}$ and $\mathrm{D}$ atoms involved. These 'statistical' patterns should be approached by the experimental abundance patterns of the metastable molecular ions due to their long lifetime. In Fig. 1 the experimental patterns are contrasted with those of five exchange models (A-E) for the penta- and nonadeuterated compounds 1e, 1f and $\mathbf{1 g}$.

Model A. Statistical equipartition of all $14 \mathrm{H}$ atoms of the two benzyl groups. As has been shown already from the data of $\mathbf{1 b}$, this model, yielding patterns similar to a normal distribution curve, is of minor significance.

Model B. Fast equilibration involving two separate sets of four H(D) atoms at the benzylic and at the two ortho positions within each benzyl group ( $\alpha-\mathrm{H} / \mathrm{o}-\mathrm{H}$ exchange'). Similarly to A, this model has to be excluded especially from the data for $1 f$.

Table 4. Relative abundances ${ }^{\mathrm{a}}$ of the $\mathrm{C}_{7}^{+}{ }^{+}$ions ${ }^{\mathrm{b}}$ from $[1]^{\dagger}$ and its deuterated analogues formed within the first field free region $\left(\approx 10^{-5}\right.$ s) after $70 \mathrm{eV}$ ionization

\begin{tabular}{rcccccccc}
\hline$m / e$ & 1 & 1a & 1b & 1c & 1d & 1o & 1f & 1g \\
91 & 0.5 & 0.5 & 1.3 &. &. &. &. &. \\
92 & $99.5^{r}$ & $99.0^{r}$ & $45.9^{r}$ & 12.3 & $14.1^{r}$ & $13.5^{r}$ & 0.5 &. \\
93 &. & 0.5 & 4.4 & $56.1^{r}$ & 58.1 & 30.0 & $6.6^{r}$ & 3.5 \\
94 &. &. & 3.5 & $31.5^{r}$ & $27.9^{r}$ & 10.1 & 21.6 & $33.4^{r}$ \\
95 &. &. & $44.9^{r}$ &. &. & 7.3 & 20.0 & 13.8 \\
96 &. &. &. &. &. & 22.6 & 9.4 & 4.2 \\
97 &. &. &. &. &. & $16.6^{r}$ & 19.1 & 16.2 \\
98 &. &. &. &. &. & & 17.9 & $29.2^{r}$ \\
99 &. &. &. &. &. & & $5.0^{r}$ & 3.4 \\
\hline
\end{tabular}

a,b See footnotes to Table 2. 


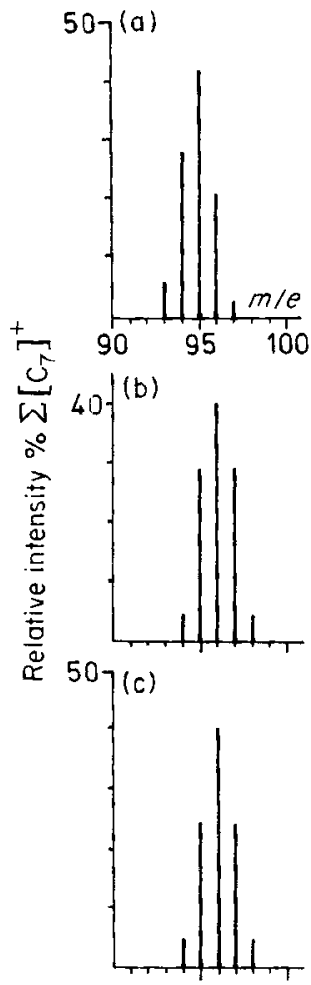

Model A

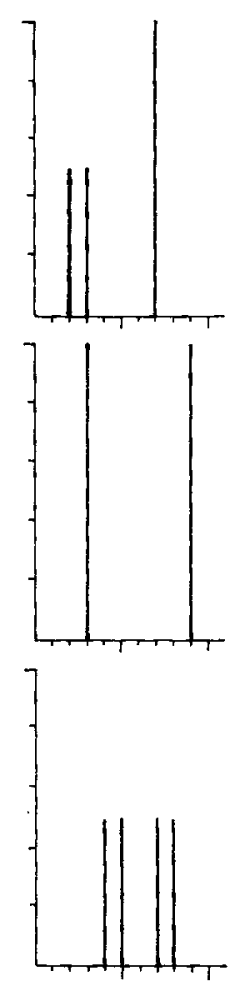

B

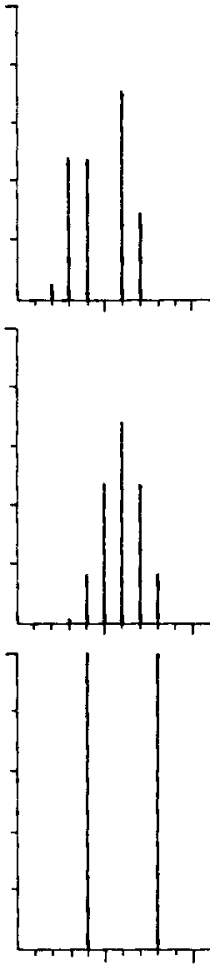

C
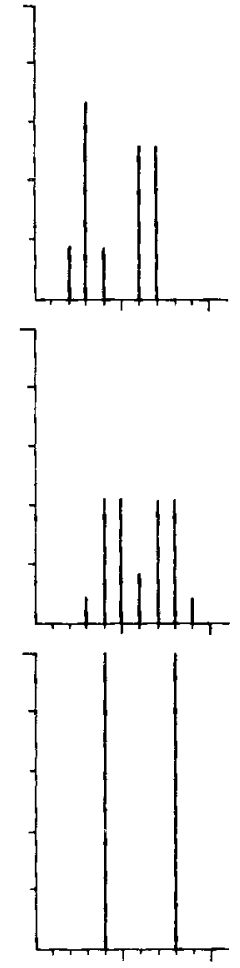

D
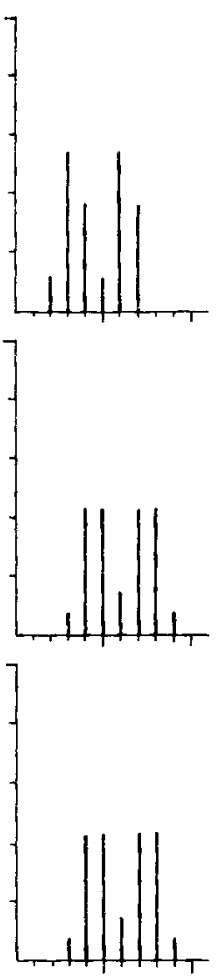

E
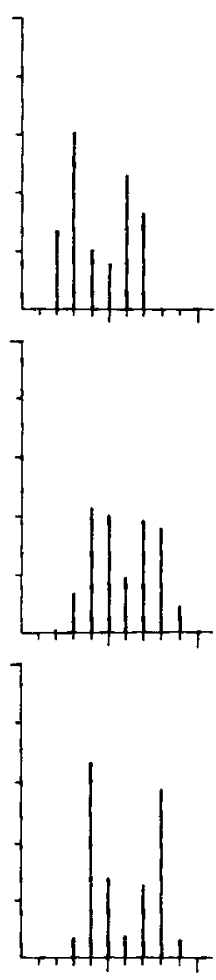

(exp.)

Figure 1. Abundance patterns of $\left[C_{7}(H, D)_{8}\right]^{\ddagger}$ from (a) 1e, (b) $1 f$ and (c) 19 for five statistical models and from the metastable molecular ions.

Model C. Exchange between the H(D) atoms of the $\gamma$-methylene group and the five $H(D)$ atoms of the $\alpha$-phenyl nucleus (and vice versa). As a main reaction pathway this mechanism can be excluded also from the data for 1b. As to a minor participation, the quantitative analysis of the abundance patterns for 1 e and 1 f indicate that even a combination with other models does not give a satisfactory agreement with the experimental data.

Model D. Repeated exchange between the H(D) atoms of the $\gamma$-methylene group and those at the ortho (o) positions of the $\alpha$-phenyl nucleus and vice vers $a$ (referred to as ' $\gamma-\mathrm{H} / 0-\mathrm{H}$ exchange' below). As can be seen most strikingly from the patterns for $\mathbf{1 g}$, this model does not explain the experimental data either.

Model E. Simultaneous equilibration involving the eight $\mathrm{H}(\mathrm{D})$ atoms at the $\gamma, \alpha$ and ortho positions. Likewise, the calculations based on this model are not in line with the observed patterns, the discrepancy being of particular significance in the case of $\mathbf{1 g}$ again.

Thus, none of these five models is able to explain the experimental abundance patterns of the $\left[\mathrm{C}_{7}(\mathrm{H}, \mathrm{D})_{8}\right]^{+}$ions. Additional models-in particular those assuming charge/radical localization on a phenyl nucleus-yield considerably different abundance patterns, too.

However, a linear combination of the patterns of models $\mathrm{D}$ and $\mathrm{E}$ (assuming $c .37 \%$ of $\left[\mathrm{C}_{7}(\mathrm{H}, \mathrm{D})_{8}\right]^{+}$ being generated according to model $D)$ represents a fairly good approximation for all deuterated analogues. Not surprisingly, correspondence of the observed patterns with the combined calculated ones is not achieved completely. Generally, a combination of individual statistical distribution with each other cannot represent a statistical distribution in its turn. Thus, it follows from the fairly good correspondence of the pattern obtained from the combination of models $D$ and $E$ with the experimental pattern, that complete equilibration of all eight $H(D)$ atoms at the benzylic and at the ortho positions of the two benzyl groups cannot be reached even in the metastable ions. In this case identical $\left[\mathrm{C}(\mathrm{H}, \mathrm{D})_{8}\right]^{ \pm}$abundance patterns would be observed for both the nonadeuterated compounds 1f and 1g. Summarizing at this point, it is found that all eight $\mathrm{H}$ atoms at the $\gamma, \alpha$, ortho and ortho' positions of the metastable molecular ions of $\mathbf{1}$ are involved repeatedly in a mutual exchange. While statistical equipartition is not reached, the selective, cross-wise $\gamma-\mathrm{H} / o-\mathrm{H}$ and $\alpha-\mathrm{H} / o-\mathrm{H}$ exchange is of particular importance for the migrations of the $\mathrm{H}$ atoms.

\section{Mechanisms of $\mathrm{H}$ exchange}

In order to explain the $\gamma-\mathrm{H} / 0-\mathrm{H}$ exchange in the molecular ions of $\mathbf{1}$, the formation of an intermediate $[\mathrm{Z}]^{ \pm}$is assumed, formed by $\gamma-\mathrm{H}$ transfer to one of the corresponding ortho positions (marked ' $\gamma \rightarrow o$ ' in Scheme 2). Subsequently, $[\mathrm{Z}]^{+}$can react in three different ways: (i) re-formation of the original $[1]^{ \pm}$by transfer of $\gamma-\mathrm{H}$ or $\mathrm{o}-\mathrm{H}$ to the $\gamma$ position; (ii) isomerization to $[2]^{+}$( tautomer of $[\mathbf{1}]^{+}$) by transfer of $\gamma-\mathrm{H}$ or $o-\mathrm{H}$ to one of the ortho' positions of the other benzyl group; (iii) fragmentation to $\left[\mathrm{C}_{7} \mathrm{H}_{8}\right]^{ \pm}$and $\mathrm{C}_{8} \mathrm{H}_{8}$ by simple cleavage of the $\alpha, \beta$ carbon-carbon bond.

Reaction channel (ii), i.e. $o \rightarrow o^{\prime}$ transfer, enables $[\mathbf{1 g}]^{+}$to form $\left[\mathrm{C}_{7}(\mathrm{H}, \mathrm{D})_{8}\right]^{+}$fragment ions of $\mathrm{m} / \mathrm{e} 93$, $95,96,97$ and 99 , besides $\left[\mathrm{C}_{7} \mathrm{H}_{6} \mathrm{D}_{2}\right]^{\star}(m / e 94)$ and 


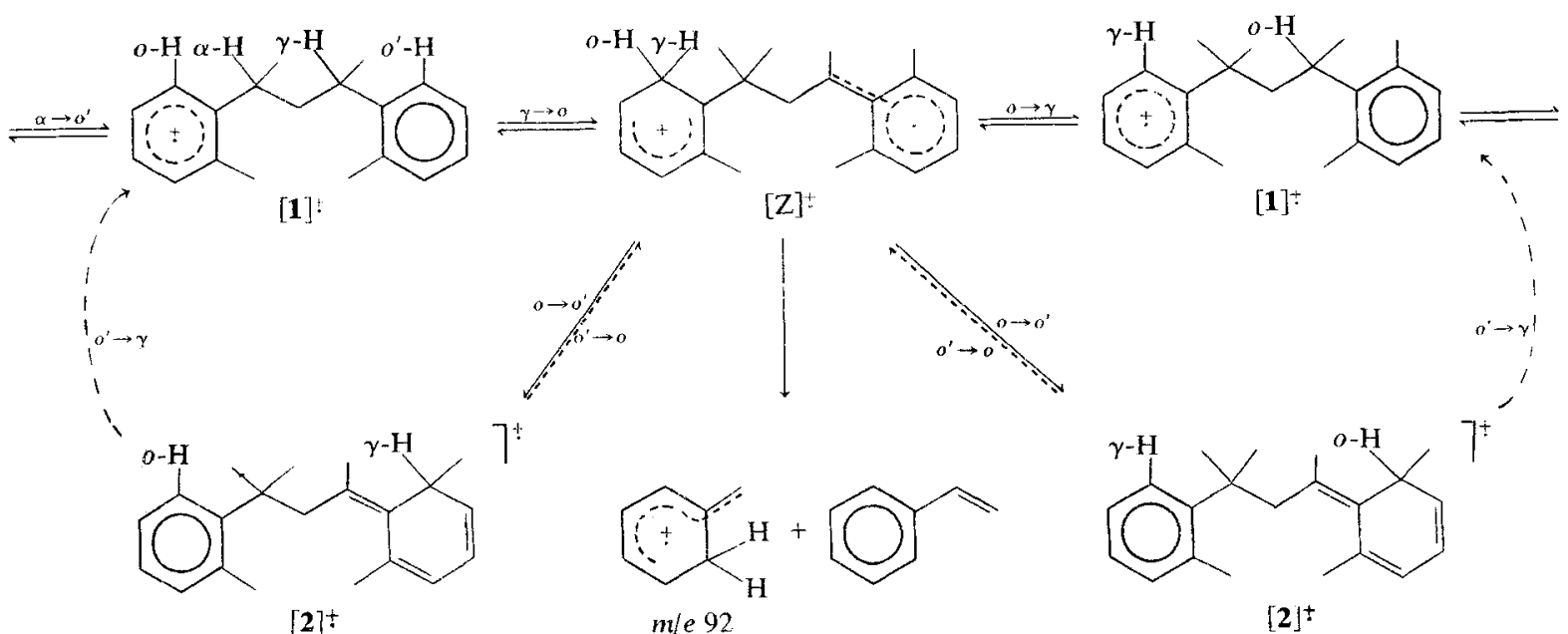

$[2]^{+}$

nile 92

$[2]$

Scheme 2. $\mathrm{H}$ migrations in the molecular ions of 1 (for dashed lines see text).

$\left[\mathrm{C}_{7} \mathrm{H}_{2} \mathrm{D}_{6}\right]^{+}(\mathrm{m} / \mathrm{e} 98)$ which result from a simple $\gamma-\mathrm{H} / 0-$ $\mathrm{H}$ exchange $(\gamma \rightarrow o$, see Tables 3 and 4$)$. The interconversion $[1]^{+} \rightleftharpoons[\mathrm{Z}]^{+}$alone would lead to a cross-wise exchange of the $\gamma-\mathrm{H}$ and $o-\mathrm{H}$ as well as of the $\alpha-\mathrm{H}$ and $o^{\prime}-\mathrm{H}$ atoms. Contrary to the molecular ions of simple 1-phenylalkanes, the second additional isomerization pathway (ii) connects the two sets of four exchanging $\mathrm{H}$ atoms, thus giving a $\gamma-\mathrm{H} / o-\mathrm{H} / o^{\prime}-\mathrm{H}$ and an $\alpha-\mathrm{H} / o^{\prime}-\mathrm{H} / o-\mathrm{H}$ exchange, respectively. Assuming a fast fluctuation of the charge and the radical site within each molecular ion (vide supra), both of these exchange processes are linked with each other, finally yielding a $\mathrm{H}$ exchange between all of the eight positions involved (' $\gamma-\mathrm{H} / o-\mathrm{H} / \alpha-\mathrm{H} / o-\mathrm{H}$ ' exchange).

\section{Mean number of exchange cycles}

The mechanistic concept of Scheme 2 has been the basis for calculating the abundance distribution of the $\mathrm{C}_{7}$ ions as a function of the mean number $n$ of $\mathbf{H}$ exchange cycles that occur in a (standardized) molecular ion. Similar approaches were used in two investigations on $\mathrm{H}$ exchange reactions in the molecular ions of diphenylmethyl derivatives. ${ }^{5}$ If the mechanism proves to be right, the $C_{7}$ patterns observed for all labelled analogues of 1 should coincide with the calculated ones for the same value of $n$.

Actually the method is only a rough approximation. Thus, isotope effects $\left(i=k_{\mathrm{H}} / k_{\mathrm{D}}\right)$ are not taken into account for the exchange cycles but only for the $\gamma-\mathrm{H}$ transfer which directly precedes the cleavage reaction of $[\mathrm{Z}]^{+}$to $\left[\mathrm{C}_{7}(\mathrm{H}, \mathrm{D})_{8}\right]^{+}$. Moreover, the relative probabilities of the intermediate $[Z]^{ \pm}$isomerizing to $[\mathbf{1}]^{ \pm}$or to its tautomer $[2]^{+}$can only be estimated to be approximately equal the ratio $\beta \equiv\left([Z]^{+} \rightarrow[1]^{\dagger}\right) /$ $\left(\left[\mathrm{Z}^{+} \rightarrow[1]^{ \pm}\right)+[\mathrm{Z}]^{+} \rightarrow[2]^{ \pm}\right)=0.5 \pm 0.2$. This value is derived from the abundance distribution of the $\left[\mathrm{C}_{7}(\mathrm{H}, \mathrm{D})_{8}\right]^{+}$ions of $[\mathbf{1 g}]^{+}$, which is peculiarly sensitive to an alteration of $\beta$ [unlike that of 1 for example; see Fig. 2 and curve $-0-0$ in Fig. 4(b)]. Further, no allowance is made for energy distribution $P(E)$ of the molecular ions which gives rise to a corresponding distribution of individual numbers of $\mathbf{H}$ exchange cycles $P\left(n_{\mathrm{i}}\right)$. Assuming no strongly asymmetric distribution $P\left(n_{\mathrm{j}}\right)$, considerable discrepancies

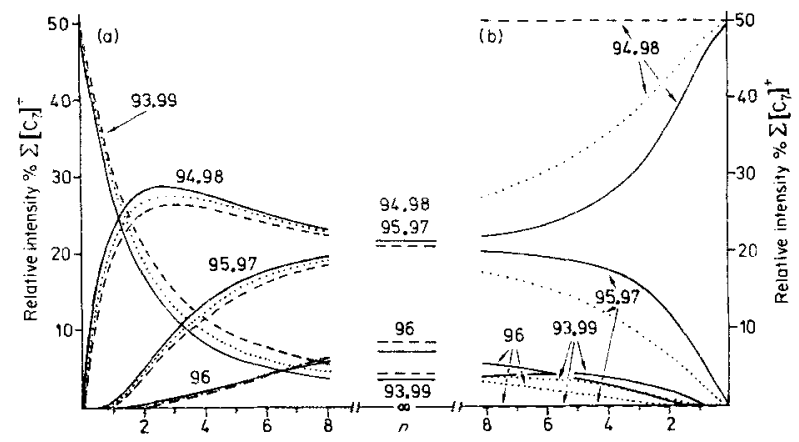

Figure 2. Effect of the competition factor $\beta=$ $\left.\left.(Z]^{+} \rightarrow[1]^{+}\right) /\left([Z]^{+} \rightarrow[1]^{ \pm}\right)+\left([Z]^{+} \rightarrow[2]^{ \pm}\right)\right)$on the variation of the $\left[C_{7}(H, D)_{8}\right.$ abundance patterns with the number $n$ of exchange cycles, calculated for (a) 1 f and (b) $1 \mathrm{~g} . \longrightarrow \beta=0, \ldots, \beta=$ $0.5,----\beta=1$.

between the calculated and the observed $\mathrm{C}_{7}$ abundance patterns have to be expected only in the vicinity of eventual extremes in single abundance curves and if $P\left(n_{i}\right)$ is rather large thus levelling them. Additionally, it is assumed in the calculations that the tautomeric $[2]^{+}$ion isomerizes directly to $[1]^{+}$by $o^{\prime} \rightarrow \gamma$ or $o \rightarrow \alpha$ migration. However, the assumption of such $1.3 \mathrm{H}$

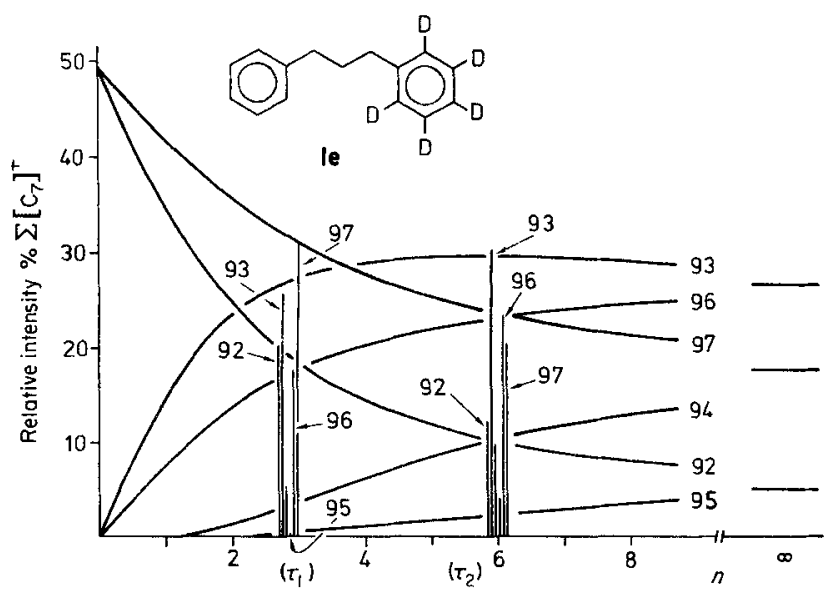

Figure 3. Calculated and observed abundance patterns for $12 \mathrm{eV}$ 'unstable' $\left(\tau_{1}\right)$ and $70 \mathrm{eV}$ metastable $\left(\tau_{2}\right)$ molecular ions of 1e. (Isotope effects of $1.00<i \leqslant 1.25$ do not alter the curves essentially). 

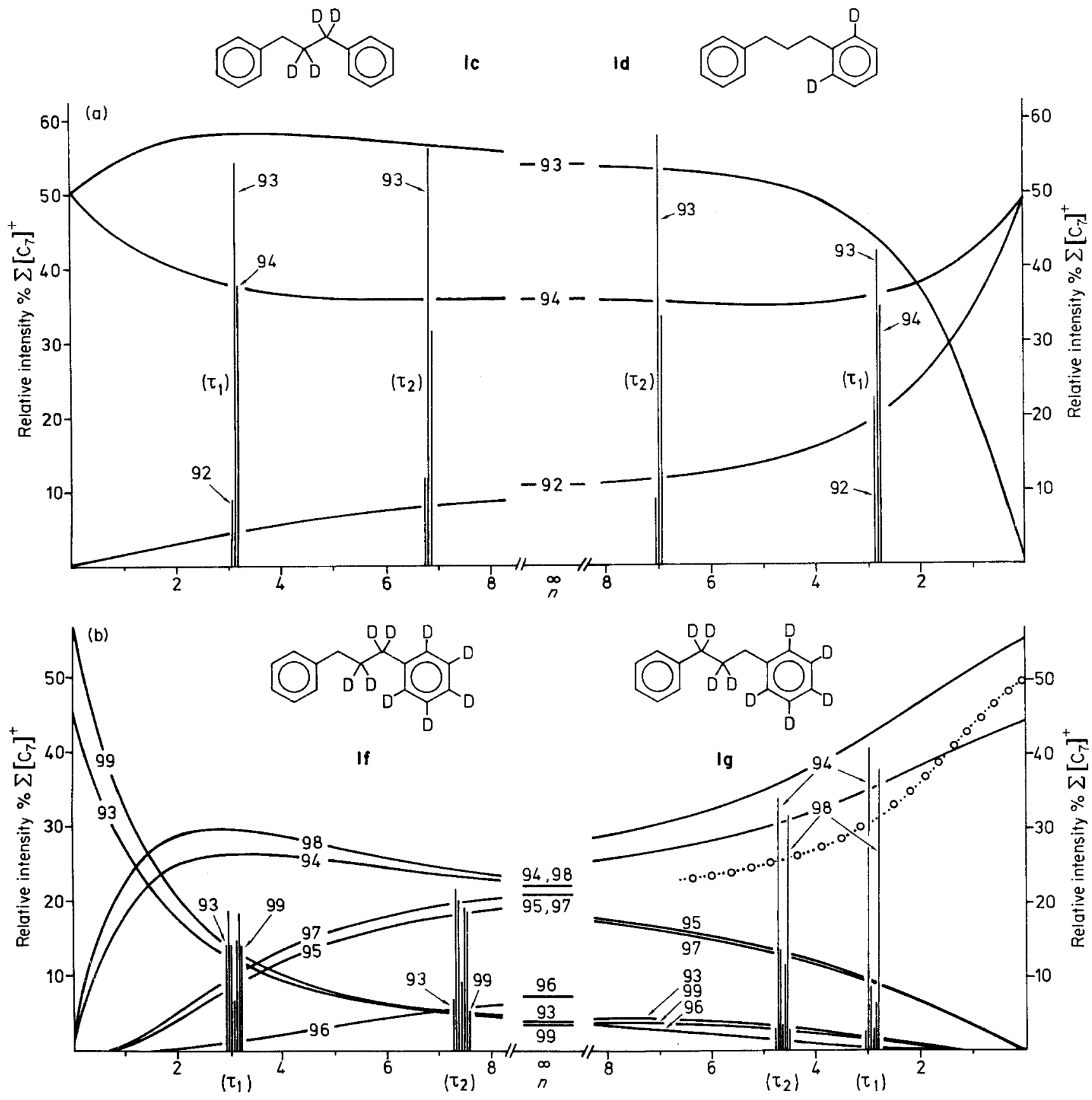

Figure 4. Calculated and observed abundance patterns for $12 \mathrm{eV}$ 'unstable' $\left(\tau_{1}\right)$ and $70 \mathrm{eV}$ metastable $\left(\tau_{2}\right)$ molecular ions of $1 \mathrm{c}$ and $1 \mathrm{~d}$ (a) and 1 and $1 \mathrm{~g}(\mathrm{~b})$, respectively. For $1 \mathrm{c}$ and $1 \mathrm{~d}$ : $i=1.00(i=1.25$ yields no essential alteration); for 1 and $1 \mathrm{~g}$ : $i=1.25$. $\cdots 0 \cdots 0 \cdots 0 \cdots=[94]$ and [98] from $1 \mathrm{~g}$, assuming $\beta=0$ (and $i=1$ ).

shifts (being symmetry forbidden in neutral molecules), should not abrogate significantly the calculated curves, as compared with the consideration of the complete isomerization sequence $[2]^{ \pm} \rightarrow[\mathrm{Z}]^{+} \rightarrow[1]^{\ddagger}$.

Figures 3 and 4 represent the calculated variation of the abundance distribution of the $\left[\mathrm{C}_{7}(\mathrm{H}, \mathrm{D})_{8}\right]^{ \pm}$ions from $[\mathbf{1 c}]^{ \pm}$to $[\mathbf{1 g}]^{ \pm}$with the number $n$ of the exchange cycles. The experimental patterns, shown in the figures as bar graphs, are corrected as far as possible for incomplete $\mathrm{D}$ labelling of the molecular ions (see Tables 1, 3 and 4). In the case of the metastable molecular ions, good agreement is found for all compounds in the range of $5 \leqslant n \leqslant 8$. It should be noted that the individual differences for the abundant $\left[\mathrm{C}_{7}(\mathrm{H}, \mathrm{D})_{8}\right]^{+}$ions do not much exceed the limits of experimental error which, in turn, are enhanced in the case of ions of low abundance. Higher and lower exchange numbers (e.g. $n \rightarrow \infty$ ) can be ruled out clearly from the data for $[\mathbf{1 e}]^{+}$and $[\mathbf{1 g}]^{+}$.

By way of comparison, the more energetic molecular ions being generated by $12 \mathrm{eV}$ electrons and fragmenting within $10^{-6} \mathrm{~s}$ exhibit a significantly lower number of exchange cycles: good agreement is found again for $[\mathbf{1 c}]^{+},[\mathbf{1 d}]^{+},[\mathbf{1 e}]^{+}$and $[\mathbf{1 g}]^{+}$in the range of $2<n<4$. The $\left[\mathrm{C}_{7}(\mathrm{H}, \mathrm{D})_{8}\right]^{ \pm}$pattern of $[\mathbf{1 f}]^{ \pm}$is an exception because only a qualitative agreement is observed. As can be seen from Fig. 2, this discrepancy is not due to an effect of the value of $\beta$. It becomes intelligible, however, if allowance is made for the fact that the curves for the abundant $\left[\mathrm{C}_{7} \mathrm{H}_{6} \mathrm{D}_{2}\right]^{ \pm}$and $\left[\mathrm{C}_{7} \mathrm{H}_{2} \mathrm{D}_{6}\right]^{t}$ 

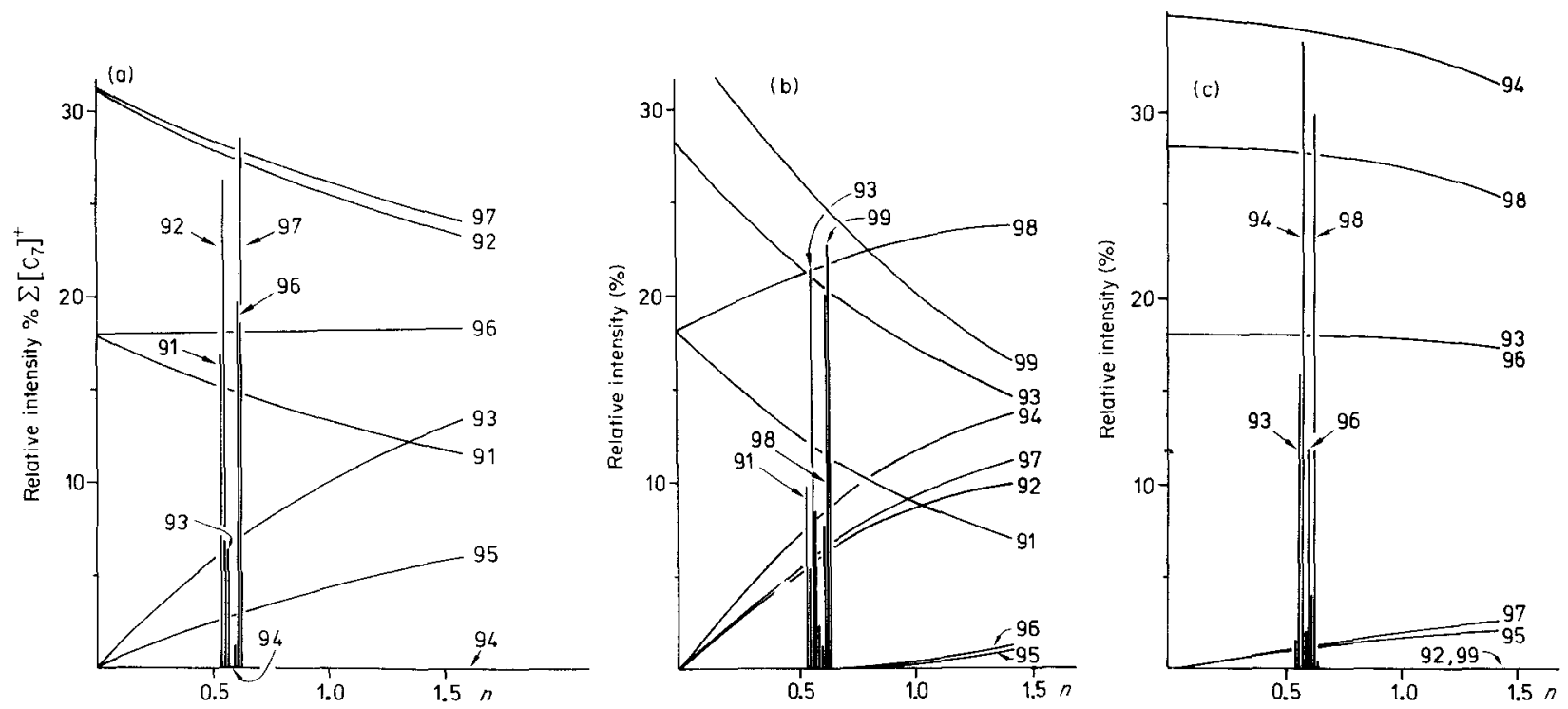

Figure 5. Calculated and observed abundance patterns of the superimposed $\left[\mathrm{C}_{7}(\mathrm{H}, \mathrm{D})_{7}\right]^{+}$and $\left[\mathrm{C}_{7}(\mathrm{H}, \mathrm{D})_{8}\right]^{+}$ions at $70 \mathrm{eV}$ for 'unstable' molecular ions (a) 1e, (b) $1 f$ and (c) 1g. For 1 e: $i=1.00,(i=1.25$ effects no observable change; for 1 if and $1 \mathrm{~g}: i=1.25$.

ions ( $m / e 94$ and 98 , respectively) exhibit distinct maxima just at $n \approx 3$. The maxima would be removed by a calculation including the real distribution over all individual values of $n$. It is interesting to note that the experimental $\left[\mathrm{C}_{7}(\mathrm{H}, \mathrm{D})_{8}\right]^{ \pm}$pattern for $\mathbf{1 f}$ is peculiarly sensitive to alterations of electron energy (see also previous discussion on the energy distribution).

The formation of the $\left[\mathrm{C}_{7} \mathrm{H}_{8}\right]^{t}$ ions from the molecular ions of 1-phenylbutane is accompanied by an isotope effect of $i=1.25$ at $70 \mathrm{eV}^{5}$ Comparing the experimental $\left[\mathrm{C}_{7}(\mathrm{H}, \mathrm{D})_{8}\right]^{+}$patterns (especially $m / e \quad 94$ vs $m / e 98$ from $[\mathbf{1 f}]^{+}$and $[\mathbf{1 g}]^{\dagger}$ ) with the corresponding calculated abundance distributions reveals isotope effects within the range of $1.0<i<2$.

The $\mathbf{H}$ transfer reactions outlined in Scheme 2 take place in a similar way in the more excited, short-lived molecular ions that are generated at $70 \mathrm{eV}$ and fragment within the ion source (Table 2). For calculating the abundance distribution the contribution of the $\left[\mathrm{C}_{7}(\mathrm{H}, \mathrm{D})_{7}\right]^{+}$ions must be considered. It can be shown by further model calculations within the scope of this study that the $\left[\mathrm{C}_{7}(\mathrm{H}, \mathrm{D})_{7}\right]^{+}$ions originate mostly (to $>90 \%$ ) direct from $[1]^{+}$, i.e. the consecutive fragmentation from $\left[\mathrm{C}_{7}(\mathrm{H}, \mathrm{D})_{8}\right]^{+}$via loss of $\mathrm{H}^{\cdot}$ or $\mathrm{D}$. represents less than $10 \%$ of the total formation of $\left[\mathrm{C}_{7}(\mathrm{H}, \mathrm{D})_{7}\right]^{+}$within the ion source. This is in accord with the results on simple 1 -phenylalkanes. ${ }^{3}$

Using the abundance ratio $\left[\mathrm{C}_{7} \mathrm{H}_{7}\right]^{+} /\left[\mathrm{C}_{7} \mathrm{H}_{8}\right]^{+}=0.579$, and assuming that both of the fragmentation processes are preceded by the same number of exchange cycles and that $\beta=0.5$ (vide supra) holds for the more excited molecular ions as well, the abundance curves shown in Fig. 5 are obtained. Here again, an isotope effect $i \approx 1.25$ is operative, although hardly observable in the case of $[\mathbf{1 e}]^{+}$. Agreement between the experimental and the calculated abundances patterns is good or at least satisfactory for all three analogues (as well as for $[\mathbf{1 c}]^{\ddagger}$ and $[\mathbf{1 d}]^{+}$, not illustrated here) in the range of $0.4<n<0.8$. Thus, on the average, only every second molecular ion, generated at $70 \mathrm{eV}$ and fragmenting to $\left[\mathrm{C}_{7} \mathrm{H}_{7}\right]^{+}$and $\left[\mathrm{C}_{7} \mathrm{H}_{8}\right]^{+}$within the ion
Table 5. Mean life time $\tau$ and mean number $n$ of exchange cycles in the molecular ions of 1,3-diphenylpropane (1)

\begin{tabular}{cccc}
\hline$\tau \mid \mu \mathrm{s}\}$ & $\ll 1$ & $\leqslant 1$ & $\approx 10$ \\
$n$ & $0.4<n<0.8$ & $2<n<4$ & $5 \leqslant n \leqslant 8$ \\
\hline
\end{tabular}

source, undergoes a $\mathrm{H}$ exchange cycle $[1]^{+} \rightleftharpoons[\mathrm{Z}]^{\star}$ or $[\mathbf{1}]^{+} \rightleftharpoons[\mathrm{Z}]^{+} \rightleftharpoons[\mathbf{2}]^{+}$

Summarizing, the (mean) number of exchange cycles in $[1]^{+}$depends markedly on the mean lifetime of the molecular ions changing by a factor of about 10 within the time scale accessible by the mass spectrometric techniques used (Table 5).

\section{DISCUSSION}

It is found as a first important result of the present study that the molecular ions of 1,3-diphenylpropane (1) isomerize only insignificantly by skeletal rearrangements (of the toluene/cycloheptatriene type ${ }^{7}$ ) before fragmenting to $\left[\mathrm{C}_{7} \mathrm{H}_{8}\right]^{+}$and $\left[\mathrm{C}_{7} \mathrm{H}_{7}\right]^{+}$, respectively. This is shown directly by the non-participation of the meta and para hydrogen atoms in the $\mathrm{H}$ exchange processes, as well as indirectly by contrasting the calculated (models A and B) and the observed abundance distributions of the $\left[\mathrm{C}_{7} \mathrm{H}_{8}\right]^{ \pm}$ions. Moreover, ring expansion reactions of $[1]^{ \pm}$can be ruled out by the mass spectral investigation of 1-(7-cycloheptatrienyl)-2phenylethane (3) and its phenyl- $d_{s}$ analogue. ${ }^{8}$ Apart

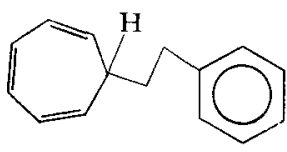

3

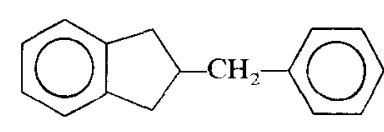

4 from skeletal isomerizations, $\mathrm{H}$ exchange processes within each of the benzyl groups do not play a significant part either. Thus, sigmatropic $[1,3]$ or $[1,2] \mathrm{H}$ 
shifts, which occur in the molecular ions of toluene ${ }^{9}$ and tetralol ${ }^{10}$ are not observed here (see model B). Correspondingly, the $\alpha-\mathrm{H}$ (as well as the meta and para hydrogen) atoms of the molecular ions of 2benzylindan (4), which is similar to 1 , are fixed at their original positions. ${ }^{11}$ The observation that, in $[1]^{+}$, the only mobile aromatic $\mathrm{H}$ atoms are those at the ortho positions, is of particular interest with respect to $H$ exchange reactions that were found by a number of authors to occur in the proton addition complexes of aromatic compounds both in solution ${ }^{12}$ and in the gas phase $^{13}$ (vide infra).

Obviously, these isomerization processes within each of the benzyl groups of [1] $]^{\dagger}$ cannot compete-at all of the studied ranges of lifetime-with the $H$ transfer reactions between both of the benzyl groups. As has been deduced from substituent effects, ${ }^{1}$ the repeated mutual exchange between the $\gamma-\mathrm{H}$ and $o-\mathrm{H}$ atoms within c. $10 \mu \mathrm{s}$ reveals unequivocally that the isomerization $[\mathbf{1}]^{ \pm} \rightarrow[\mathrm{Z}]^{ \pm}$is considerably more favourable than the overall fragmentation $[1]^{ \pm} \rightarrow[\mathrm{Z}]^{+} \rightarrow$ $\left[\mathrm{C}_{7} \mathrm{H}_{8}\right]^{+}$. In this context it should be noted that a one-step $H$ exchange mechanism via a (non-classical) transition state [Scheme $3(\mathrm{~A})$ ] can be ruled out because it certainly has a much higher energy barrier than the two-step mechanism via the (classical) intermediate $[\mathrm{Z}]^{\ddagger}[$ Scheme $3(\mathrm{~B})]$. The former mechanism was formulated in order to explain $\mathrm{H}$ exchange phenomena in $\mathrm{N}$-alkylpyrroles, ${ }^{14}$ aliphatic ketones ${ }^{15}$ and 1-phenylheptenes. ${ }^{16}$ The energy requirements for the two-step exchange should be determined by the activation energy for the abstraction of the $\gamma-\mathrm{H}$ by the ionized phenyl nucleus, which is probably lower than the activation energy of $\mathbf{H}$ transfer from toluene to the methyl radical $\left(E_{\mathrm{a}} \leqslant 10 \mathrm{kcal} \mathrm{mol}^{-117}\right)$.

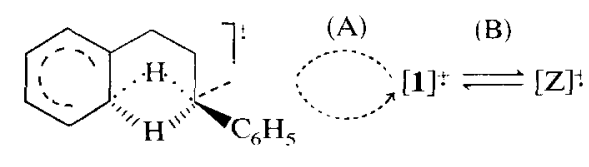

Scheme 3

Striking evidence for the two-step mechanism for the $\gamma-\mathrm{H} / o-\mathrm{H}$ exchange is given by the $o \rightarrow o^{\prime} \mathrm{H}$ transfer. The formation of the key intermediate $[\mathrm{Z}]^{+}$is indispensable for this additional migration pathway, thus enabling the indirect exchange to occur between $\alpha-\mathrm{H}$ and $\boldsymbol{o}-\mathrm{H}$ (as well as between $\gamma-\mathrm{H}$ and $o^{\prime}-\mathrm{H}$ ). This does not occur directly in the case of $[1]^{ \pm}$for energetic reasons. As compared with the molecular ions of higher 1-phenylalkanes (as well as of 4), the second aromatic nucleus may be considered to be an intramolecular 'catalyst' for the $\alpha \rightarrow o$ migration within the benzyl groups. A similar concept has been developed by Winnik. ${ }^{18}$

In order to decide whether the isomerization processes shown in Scheme 2 take place by transfer of a proton, a $\mathrm{H}$ atom or a hydride ion, the enthalpies of formation of the isomers $[\mathbf{1}]^{+},[\mathrm{Z}]^{*}$ and $[\mathbf{2}]^{ \pm}$have been calculated from thermochemical data. In contrast to $\mathbf{1}$, the hydrocarbons $\mathrm{Z}$ and $\mathbf{2}$ are distinguished both by two different $\pi$-electron systems. As a consequence, in both cases two 'electromers' can be anticipated, which are defined by the indices $\alpha$ and $\gamma$ respectively, indicating the charged ring (see Scheme 5).

The isomerization $[1]^{+} \rightarrow[\mathrm{Z}]_{\alpha}^{+}$was shown in the previous paper ${ }^{1}$ to be nearly thermoneutral, $\Delta H_{\mathrm{f}}\left([\mathbf{1}]^{\dagger}\right)=$ $228 \mathrm{kcal} \mathrm{mol}^{-1}$ and $\Delta H_{\mathrm{f}}\left([\mathrm{Z}]_{\alpha}^{+}\right)=231 \mathrm{kcal} \mathrm{mol}^{-1}$. The enthalpy of formation of the corresponding 'electromer' $[\mathrm{Z}]_{\gamma}^{+}$is estimated to be considerably higher, $\Delta H_{\mathrm{f}}\left([\mathrm{Z}]_{\gamma}^{+}\right) \geqslant 252 \mathrm{kcal} \mathrm{mol}^{-1}$, by considering the following hypothetical addition reaction (Scheme 4 ). The

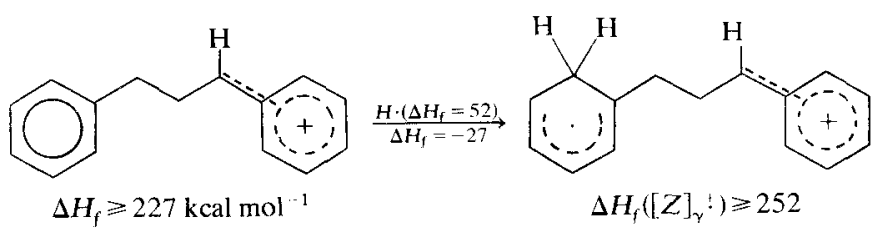

Scheme 4

addition of a $\mathbf{H}$ atom to the 1,3-diphenylprop-3-yl cation should be exothermal by c. $27 \mathrm{kcal} \mathrm{mol}^{-1}$ in analogy to $\mathrm{C}_{6} \mathrm{H}_{6}+\mathrm{H}^{\circ} \rightarrow \mathrm{C}_{6} \mathrm{H}_{7} \cdot$. This value is estimated using the enthalpies of formation of $\mathrm{C}_{6} \mathrm{H}_{6}$ $\left(19.8 \mathrm{kcal} \mathrm{mol}^{-1}\right),{ }^{19 \mathrm{a}} \mathrm{H}^{\cdot}\left(52.1 \mathrm{kcal} \mathrm{mol}^{-1}\right)^{19 \mathrm{a}}$ and of the cyclohexadienyl radical $\left(45 \mathrm{kcal} \mathrm{mol}^{-1}\right) .{ }^{22 \mathrm{~b}}$ The enthalpy of formation of the above cation is obtained assuming that the ionization energy for the corresponding radical $I\left(\mathrm{C}_{6} \mathrm{H}_{5} \mathrm{CH}_{2} \mathrm{CH}_{2} \mathrm{CH}^{\circ} \mathrm{C}_{6} \mathrm{H}_{5}\right)$ is similar to $I\left(p-\mathrm{CH}_{3} \mathrm{C}_{6} \mathrm{H}_{4} \mathrm{CH}_{2}{ }^{\circ}\right)=7.45 \mathrm{eV}^{19 \mathrm{c}}$ and that $\Delta H_{\mathrm{f}}\left(\mathrm{C}_{6} \mathrm{H}_{5} \mathrm{CH}_{2} \mathrm{CH}_{2} \mathrm{CH}^{\cdot} \mathrm{C}_{6} \mathrm{H}_{5}\right)=\Delta H_{\mathrm{f}}(\mathbf{1})+\mathrm{D}\left(\mathrm{C}^{\gamma}-\mathrm{H}\right)-$ $\Delta H_{\mathrm{f}}(\mathrm{H} \cdot)=29^{1}+78^{20}-52 \mathrm{kcal} \mathrm{mol}^{-1}=55 \mathrm{kcal} \mathrm{mol}^{-1}$.

The enthalpy of formation of $[2]_{\alpha}^{+}$, which is the tautomer of [1]ः (Scheme 5), should be similar to that of ionized ethylbenzene substituted by a (neutral) cycloheptatrienyl group at the $\beta$ position, i.e. $\Delta H_{\mathrm{f}}\left([\mathbf{2}]_{\alpha}^{+}\right) \cong$ $\Delta H_{\mathrm{f}}\left([3]_{\mathrm{ph}}^{+}\right)$, yielding $\Delta H_{\mathrm{f}}\left([2]_{\alpha}^{+}\right) \cong \approx 256 \mathrm{kcal} \mathrm{mol}^{-1}$ as follows. ${ }^{21}$ Using group equivalents, ${ }^{19 a} \Delta H_{\mathrm{f}}(3)$ is estimated to be $c .59 \mathrm{kcal} \mathrm{mol}^{-1}$. Ionization of the phenyl nucleus of $2\left(\rightarrow[2]_{\alpha}^{+}\right)$should require approximately the same energy as for $\mathrm{C}_{6} \mathrm{H}_{5}-n \mathrm{C}_{4} \mathrm{H}_{9} I(\mathrm{M})=8.67 \pm 0.08 \mathrm{eV}$ (Refs. 4, 19a, 21) and for $1 I(\mathbf{1})=8.60 \pm 0.1 \mathrm{eV}^{1}$ As against that the formation of the corresponding 'electromer' $[2]_{\gamma}^{+}$, being ionized in the (olefinic) hexatriene system, should be much more favourable. $[2]_{\gamma}^{+}$is a derivative of the 5-methylene-cyclohexa-1,3-diene radical cation $\left[\mathrm{C}_{7} \mathrm{H}_{8}\right]^{ \pm}$(formed from 1 for example), whose enthalpy of formation, contrasting to Williams' and Bowen's value, ${ }^{22}$ is found to be very similar to that of ionized toluene: $\Delta H_{\mathrm{f}}\left(\left[\mathrm{C}_{7} \mathrm{H}_{8}\right]^{+}(\mathbf{1}) \leqslant 216 \mathrm{kcal}\right.$ mol. ${ }^{1,23}$ Consequently, by analogy with the $\left[\mathrm{C}_{6} \mathrm{H}_{5}\right.$ $\left.\mathrm{CH}_{3}\right]^{+}$derivative $[\mathbf{1}]^{+}, \Delta H_{\mathrm{f}}\left([\mathbf{2}]_{\dot{\gamma}}^{+}\right)$should be less than $230 \mathrm{kcal} \mathrm{mol}^{-1}$.

Thus, both isomers $[\mathrm{Z}]^{+}$and $[2]^{+}$should be ionized in the olefinic part in their electronic ground states. It is interesting to note that not only $[Z]_{\alpha}^{+}$but also $[2]_{\gamma}^{+}$is formed by thermoneutral reactions substantiating the similar probabilities of the $H$ transfer steps $[Z]_{\alpha}^{+} \rightarrow[1]^{ \pm}$ and $[\mathrm{Z}]_{\alpha}^{+} \rightarrow[2]_{\gamma}^{+}$, i.e. $\beta \approx 0.5$ (vide supra, Scheme 2 ). As the threshold for the fragmentation to $\left[\mathrm{C}_{7} \mathrm{H}_{8}\right]^{t}$ is considerably higher $\left(c .1 .1 \mathrm{eV}^{1}\right)$ an efficient interconversion between $[1]^{t},[\mathrm{Z}]_{\alpha}^{+}$and $[2]_{\gamma}^{+}$is achieved, the extent increasing with decreasing excitation energy. The formation of the 'electromers' $[\mathrm{Z}]_{\dot{\gamma}}^{+}$and $[2]_{\alpha}^{+}$, on the other hand, requires more energy than the fragmentation to $\left[\mathrm{C}_{7} \mathrm{H}_{8}\right]^{+}$and cannot compete with the cleavage of the 


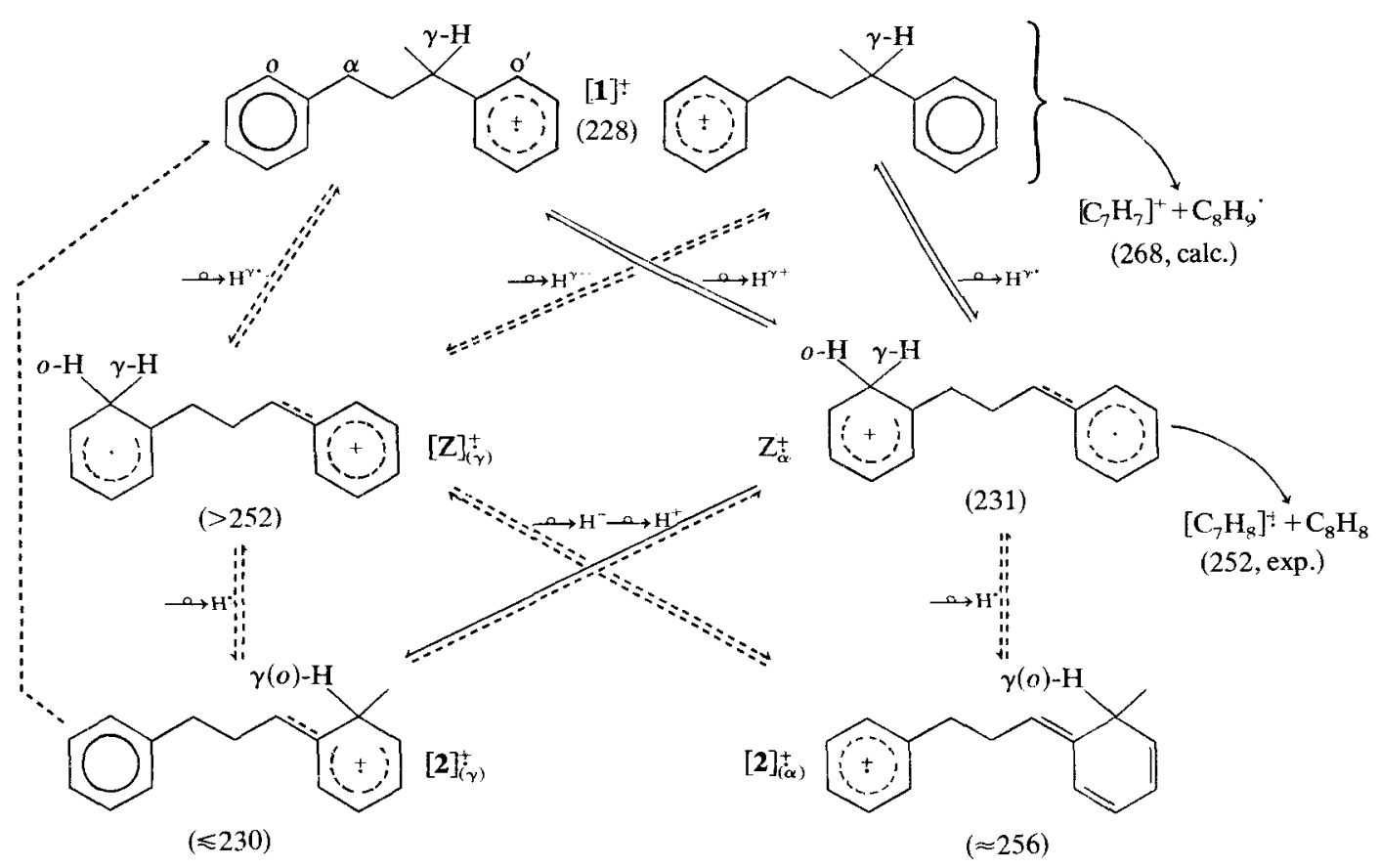

Scheme 5. Isomerization occurring in the molecular ions of 1 before fragmentation to $\left[\mathrm{C}_{7} \mathrm{H}_{7}\right]^{+}$and $\left[\mathrm{C}_{7} \mathrm{H}_{8}\right]^{+}$. Values refer to the corresponding enthalpies of formation in $\mathrm{kcal} \mathrm{mol}^{-1}$. Full arrows represent main reaction paths (see text).

$\alpha, \beta \mathrm{C}-\mathrm{C}$ bond of $[\mathrm{Z}]_{\alpha}^{+}$(Scheme 5). Furthermore, the non-participation of $[\mathrm{Z}]_{\gamma}^{+}$is supported by the finding that no $\mathrm{H}$ migrations occur within the benzyl groups which should be anticipated for such an $\alpha$ substituted benzyl cation.

As illustrated in Scheme 5, the isomerization [1 $]^{+} \rightarrow$ $[\mathrm{Z}]_{\alpha}^{+}$can be achieved both by transfer of $[\mathrm{H}]^{+}$and $\mathrm{H}^{*}$. However, the abundance ratios of the $\left[\mathrm{C}_{7} \mathrm{H}_{7} \mathrm{X}\right]^{+}$ions $\left(\mathrm{X}=\mathrm{H}, \mathrm{OCH}_{3}\right.$ and $\mathrm{CF}_{3}$ ) from the methoxy and trifluoromethyl derivatives of 1 suggest the migration of a $\mathrm{H}^{\circ}$ atom. Such a reaction is in analogy to the McLafferty 'rearrangement' of carbonyl compounds and to ion-molecule reactions like $[\mathrm{Ar}]^{t}+\mathrm{H}_{2} \rightarrow$ $[\mathrm{ArH}]^{+}+\mathrm{H}^{24}$ ( $\mathrm{Ar}=$ aromatic nucleus). On the other hand, the transfer of a hydride ion can be ruled out for both $[1]^{+} \rightarrow[\mathrm{Z}]_{\alpha}^{+}$and $[\mathrm{Z}]_{\alpha}^{+} \rightarrow[2]_{\dot{\gamma}}^{+}$. Moreover, for the latter interconversion, the migration of a $\mathrm{H}^{-}$atom can be excluded too; this isomerization step represents a true proton transfer reaction between the aromatic nuclei.

The present study confirms intramolecular isomerizations on the level of the molecular ions of 1 and the two-step character of their fragmentation to $\left[\mathrm{C}_{7} \mathrm{H}_{8}\right]^{+}$, which was deduced previously from the substituent effects. Similarly to $\left[\mathrm{C}_{7} \mathrm{H}_{8}\right]^{+}$, the $\left[\mathrm{C}_{7} \mathrm{H}_{7}\right]^{+}$ions, formed by 'simple' benzylic cleavage, are produced to a considerable extent ( $\geqslant 50 \%$, see Table 5) after at least one isomerization cycle via $[\mathrm{Z}]_{\alpha}^{+}$(and $[2]_{\gamma}^{+}$). Consequently, the formation of both $\left[\mathrm{C}_{7} \mathrm{H}_{8}\right]^{+}$and $\left[\mathrm{C}_{7} \mathrm{H}_{7}\right]^{+}$is connected to the isomerization equilibrium, $[\mathrm{Z}]^{ \pm}$being the precursor of the former, and $[\mathbf{1}]^{+}$the precursor of the latter fragment ion. The third isomer $[2]_{\gamma}^{+}$, however, whose formation could not be deduced by substituent effects, ${ }^{1}$ cannot fragment to the $C_{7}$ ions directly (Scheme 5). Thus, as far as can be seen, the 'rearrangement' products $\left[\mathrm{C}_{7} \mathrm{H}_{8}\right]^{+}$are formed exclusively from $[Z]_{\alpha}^{+}$and-most convincingly-their primary structure must be that of ionized 5-methylene- cyclohexa-1,3-diene. The latter finding is of particular interest, supporting the results of Levsen and McLafferty on unimolecular ${ }^{25}$ and those of Bursey $e t$ al. on bimolecular ${ }^{26}$ secondary reactions of the $\left[\mathrm{C}_{7} \mathrm{H}_{8}\right]^{t}$ 'rearrangement' ions. It agrees also with other investigations concerning electronic ${ }^{27}$ and steric $^{28}$ effects of substituents upon the alkene elimination from the molecular ions of the appropriate 1arylalkanes, but it is contradictory to the assumptions of Williams and Bowen. 22

As compared with the fast $\mathrm{H}$ shifts in the molecular ions of small olefins, such as 2-methylpropene ${ }^{29 a}$ and cyclohexene, ${ }^{29 b}$ in which statistical equipartition of all $\mathrm{H}$ atoms occurs within $1 \mu \mathrm{s}$ and even $1 \mathrm{~ns}$, respectively, the $\mathbf{H}$ migration processes in $[1]^{+}$do not lead to complete loss of positional identity within $10 \mu \mathrm{s}$. Without discussing this point in greater detail it should be noted that the particular slowness of the $H$ exchange for 1 must be due, inter alia, to the large mean distance between the $\mathrm{H}$ donor and the $\mathrm{H}$ acceptor sites. This is in accord with an investigation of the fragmentation behaviour of higher $\alpha, \omega$-diphenylalkanes, ${ }^{11}$ suggesting that $[\mathbf{1}]^{\ddagger}$ and its higher homologues exist predominantly in open chain, flexible conformations and not as intramolecular charge transfer complexes. Thus, the significant, though only limited increase of $\mathrm{H}$ exchange within the time scale of conventional mass spectrometric techniques is a consequence of the 'long-range' $\mathrm{H}$ migrations, in contrast to the 'short-range' allylic $H$ shifts mentioned above, which are resolved only by field ion kinetics. ${ }^{29}$

\section{Intramolecular formation of $\sigma-$ and $\pi$-complexes from [1]}

The mechanism of site specific $H$ migrations in the molecular ions of $\mathbf{1}$ is of particular importance with 
respect to the properties of proton addition complexes of aromatic species that are intermediates of electrophilic aromatic substitutions. ${ }^{30} \mathrm{H}$ exchange processes represent the most simple electrophilic substitution reaction of aromatic molecules and were found to occur via $\sigma$-complexes as intermediates both in the liquid $^{12}$ and in the gas phase. ${ }^{13} \pi$-complexes which were postulated as well by some authors as intermediates, ${ }^{30 a}$ have never been observed directly.

Neglecting the radical electron in the $\gamma$ benzyl(idene) group, which is isolated by the aliphatic chain, $[\mathrm{Z}]_{\alpha}^{+}$represents a $\sigma$-complex, being generatedat least formally-by an intramolecular protonation of an alkylbenzene at an ortho position. Unlike the ortho positions, the meta and para positions of $[1]^{ \pm}$cannot be protonated directly by $H$ transfer from the $\gamma-$ (or $\alpha-$ ) methylene group. Protonation of the meta positions of the $\gamma$-phenyl nucleus of $[Z]_{\alpha}^{+}$(see Scheme 5) directly from the protonated ortho position of the $\alpha$-phenyl nucleus is, although sterically possible, much less probable.

As the present results unequivocally show, $[\mathrm{Z}]_{\alpha}^{+}$does not isomerize to the corresponding meta and/or para protonated $\sigma$-complexes $\left([\mathrm{Z}]_{\text {meta }}^{+}\right.$and $[\mathrm{Z}]_{\text {para }}^{+}$in Scheme $6 ;[Z]_{\text {ortho }}^{+}$is identical with $\left.[\mathrm{Z}]_{\dot{\alpha}}^{+}\right)$. Similarly, 'face' and 'side' protonations for the aromatic nucleus are ruled out too. The $\pi$-complexes $\left(\left[\pi_{z}\right]^{+}\right.$and $[\pi]_{i o}^{+},[\pi]_{o m}^{+}$and $[\pi]_{m p}^{+}$, respectively) would form necessarily (inter alia) the $\sigma$-complexes $[\mathrm{Z}]_{\text {meta }}^{+}$and $[\mathrm{Z}]_{\text {para }}^{+}$upon further reaction thus activating the meta and para hydrogen atoms for the $\mathrm{H}$ migrations between the benzyl groups.

According to experimental and theoretical investigations on the protonation of benzene and alkylbenzenes $^{12 \mathrm{~d}, 12 \mathrm{~g} ; 13 c, 13 \mathrm{~d}}$ the para protonated $[\mathrm{Z}]_{\text {para }}^{+}$should be the most stable of all complexes shown in Scheme 6. Although the ortho isomer $[\mathrm{Z}]_{\text {ortho }}^{+}$should be less stable by $2 \mathrm{kcal} \mathrm{mol}^{-1},{ }^{13 \mathrm{~d}}$ it is still the only complex observed. Again, the meta and ipso isomers should be less stable by 4 and $6 \mathrm{kcal} \mathrm{mol}^{-1}$, respectively. ${ }^{13 \mathrm{~d}}$ It is obvious that these enthalpy differences would not suffice to suppress completely $\mathrm{H}$ migrations within the phenyl rings ('ring walks') in favour of the observed isomerization reactions by $\mathrm{H}$ migrations between the rings $\left([\mathrm{Z}]_{\text {ortho }}^{+} \rightarrow[1]^{+}\right.$and $[\mathrm{Z}]_{\text {ortho }}^{+} \rightarrow[2]_{\gamma}^{+}$, Schemes 5 and
6 ), all the more since frequency factors for $1.2 \mathrm{H}$ shifts can be assumed to be relatively high.

More decisively, energy requirements for $\mathbf{H}$ (proton) migrations along and across the aromatic ring are very high. In super acids, the activation energy for their occurrence in protonated toluene is $10 \pm 1 \mathrm{kcal} \mathrm{mol}^{-1}$ according to Olah and co-workers. ${ }^{12 \mathrm{~d}}$ Diverging from this (solution) value, Hehre and Pople ${ }^{13 \mathrm{~g}}$ predicted activation barriers of $20-30 \mathrm{kcal} \mathrm{mol}^{-1}$ for $\mathrm{H}$ migrations along the ring of protonated (gaseous) benzene, involving $\pi$-'complexes' as transition states. $\mathrm{H}$ migrations across the ring via face protonation similar to $\left[\pi_{z}\right]^{t}$ (Scheme 6) were found to be even more unfavourable. ${ }^{13 \mathrm{~g}}$

The lack of $\mathrm{H}$ shifts within the protonated ring of $[Z]^{+}$represents an experimental corroboration of the theoretical results. The activation energy for the cleavage of $[\mathrm{Z}]_{\text {ortho }}^{+}$to $\left[\mathrm{C}_{7} \mathrm{H}_{8}\right]^{+}$and $\mathrm{C}_{8} \mathrm{H}_{8}$ is at most $c$. $25 \mathrm{kcal} \mathrm{mol}^{-1}$. ${ }^{2}$ However, the second fragmentation channel out of the equilibrium $[1]^{+} \rightleftharpoons[\mathrm{Z}]_{\text {orthor }}^{+}$i.e. cleavage of $[1]^{+}$to $\left[\mathrm{C}_{7} \mathrm{H}_{7}\right]^{+}$and $\mathrm{C}_{8} \mathrm{H}_{9}$, requires an activation energy of at least c. $40 \mathrm{kcal} \mathrm{mol}^{-1} .^{1}$ As explained above, the latter fragmentation is not preceded by $\mathrm{H}$ shifts within the aromatic nuclei either, indicating that no $\pi$-complexes are formed from those molecular ions of 1 that contain excitation energies of even c. $2.0 \mathrm{eV}$.

Thus, from the present experimental results, unsolvated $\pi$-complexes of benzene and substituted benzenes are estimated to be less stable than the corresponding unsolvated $\sigma$-complexes by at least $c$. $35 \mathrm{kcal} \mathrm{mol}^{-1}$.

\section{EXPERIMENTAL}

\section{Mass spectrometric measurements}

The 70 and $12 \mathrm{eV}$ mass spectra were obtained on a Varian MAT $\mathrm{CH}-7$ single focusing mass spectrometer (emission current $30 \mu \mathrm{A}$, source temperature $180 \pm$ $10^{\circ} \mathrm{C}$, sample pressure $<2.10^{-6}$ Torr). For low energy measurements, benzene was used as a reference $I\left(\mathrm{C}_{6} \mathrm{H}_{6}\right) \equiv 9.25 \mathrm{eV}$. Samples were introduced by the

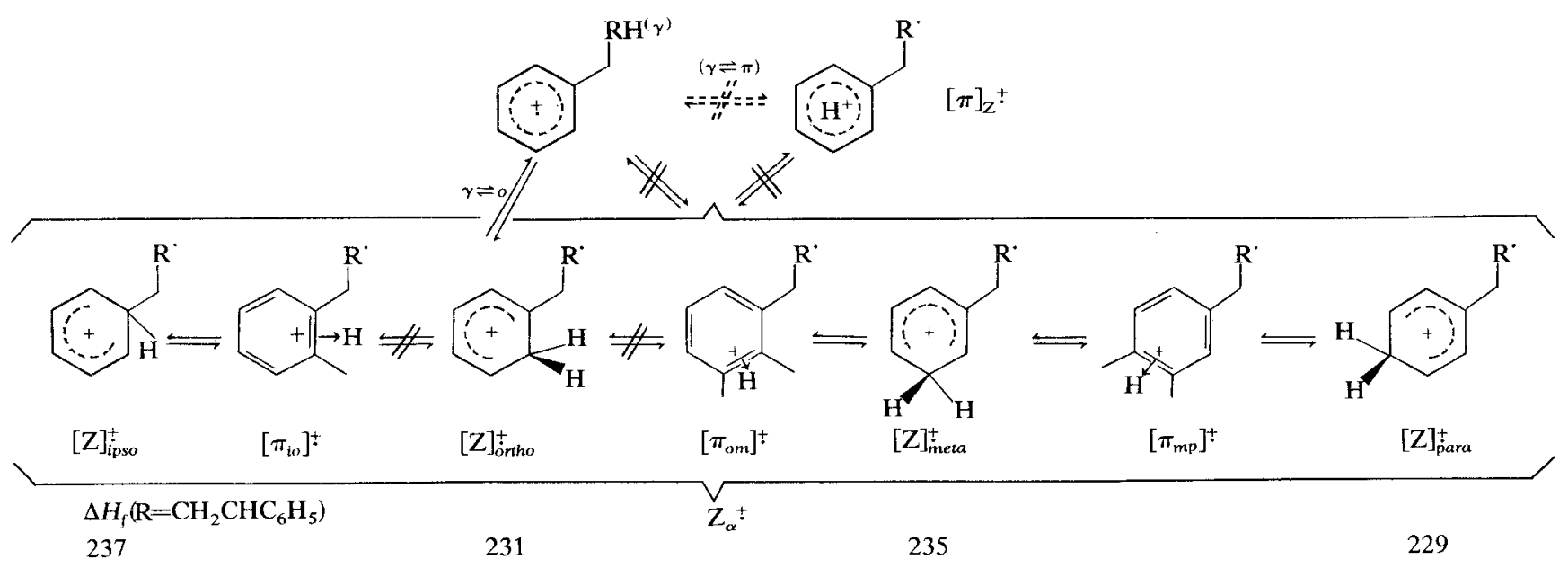

Scheme 6. Isomerization possibilities of the $\pi$ - and $\sigma$-complexes. Values refer to the corresponding enthalpies of formation $\left(\mathrm{kcal} \mathrm{mol}^{-1}\right)$. 
high temperature inlet system at $180 \pm 10^{\circ} \mathrm{C}$. The fragmentations of the metastable molecular ions were measured, at $70 \mathrm{eV}(20 \mu \mathrm{A})$, on a Varian MAT SM 1-B double focusing mass spectrometer with Mattauch-Herzog geometry by scanning the accelerating voltage with fixed electric sector and fixed magnetic field; other conditions were similar to those mentioned above. The 'metastable' measurements were repeated on a Varian MAT 311A double focusing instrument (with $\pi / 2$ magnetic deflection followed by $\pi / 2$ electric deflection) again using the accelerating voltage technique $\left(V_{0}=1 \mathrm{kV}\right)$ and the same conditions as on the $\mathrm{CH}-7$ instrument. All data given are mean values of at least three (in the case of 1a only two) independent series of measurements.

The abundance ratios of the principal peaks in the $70 \mathrm{eV}$ mass spectrum of 1 depend markedly on the focusing conditions and thus on the residence times of the ions in the source. Although variations in $\left[\mathrm{C}_{7} \mathrm{H}_{8}\right]^{ \pm} /\left[\mathrm{C}_{7} \mathrm{H}_{7}\right]^{+}$up to a factor of 2 were observed, an estimated reproducibility better than $\pm 3 \%$ was achieved for the $70 \mathrm{eV}$ data of the $\mathrm{C}_{7}$ ions formed in the source (Table 2), using the same adjustments for pusher and plates. Reproducibilities for the $C_{7}$ patterns from the $12 \mathrm{eV}$ unstable and the $70 \mathrm{eV}$ metastable molecular ions were estimated to be $\pm 5 \%$ and $\pm 10 \%$, respectively.

\section{Preparation of compounds}

Compound 1 was prepared in the conventional manner as were some of the labelled analogues (vide infra). In these cases the samples obtained were contaminated by 1,3-diphenylpropene which was removed largely by preparative gas-liquid chromatography (PGLC) using a Perkin-Elmer F 21 gas chromatograph equipped with a SE 30 column $(5 \%$ on chromosorb $G$ $\left.\left(2 \mathrm{~m}, 180^{\circ} \mathrm{C}\right)\right) .{ }^{1} \mathrm{H}$ NMR spectra were obtained on a Varian T-60 $60 \mathrm{MHz}$ spectrometer.

Deuterium incorporation data for $\mathbf{1 a}$ to $\mathbf{1 g}$ are given in Table 1.

1,3-Diphenyl-[2,2-d $\mathbf{d}_{2}$ ]propane(1a). Reduction of 1,3diphenyl-propan-2-one with $\mathrm{LiAlD}_{4}$ in the usual manner afforded 1,3-diphenyl-[2-d]propan-2-ol (82\%), b.p. $119-121^{\circ} \mathrm{C} / 0.1$ Torr. The carbinol $(3.0 \mathrm{~g}$, $14 \mathrm{mmol})$ in dry pyridine $(40 \mathrm{ml})$ was cooled to $c$. $-17^{\circ} \mathrm{C}$. With stirring $p$-toluenesulfonylchloride $(4.0 \mathrm{~g}$, $21 \mathrm{mmol})$ was added at once, and stirring was continued for $4 \mathrm{~h}$ at $-15^{\circ} \mathrm{C}$. Then the mixture was hydrolysed by carefully adding water three times $(0.3$ and then 0.6 and $1.5 \mathrm{ml}$ ) at $5 \mathrm{~min}$ intervals, keeping the temperature below $-5{ }^{\circ} \mathrm{C}$ by external cooling. Finally, water $(30 \mathrm{ml})$ was added and the crystallized product $(2.6 \mathrm{~g}, 51 \%)$, after drying, was used without further purification. After Schmidt and Karrer, ${ }^{31}$ a dry etheral solution $(8 \mathrm{ml}, 0.80 \mathrm{~g}, 2.2 \mathrm{mmol})$ of crude 1,3-diphenyl-[2- $d_{1}$ ]prop-2-yl-p-toluenesulfonate was dropped under $\mathrm{N}_{2}$ atmosphere into a suspension of $\mathrm{LiAlD}_{4}(0.20 \mathrm{~g}, 4.8 \mathrm{mmol})$ in ether $(8 \mathrm{ml})$ at $0{ }^{\circ} \mathrm{C}$. The mixture was stirred overnight at room temperature and heated under reflux for a further $6 \mathrm{~h}$. After hydrolysis with crushed ice $(5 \mathrm{~g})$, stirring with $\mathrm{NaOH}$ $(5 \mathrm{ml}, 10 \%)$ the solution was extracted with ether. After working up in the usual manner, distillation (b.p. $160-161{ }^{\circ} \mathrm{C} / 15$ Torr $)$ yielded $1 \mathrm{a}(0.25 \mathrm{~g}, 58 \%$, $>99 \%$ pure).

1-Phenyl - 3 - [3, 4, 5 - $d_{3}$ ]phenylpropane (1b). 4 - Bro moaniline $(29 \mathrm{~g}, \quad 0.17 \mathrm{~mol})$ was converted to $\left[N, N, 2,6-d_{4}\right]$-4-bromoaniline by vigorous stirring with $\mathrm{D}_{2} \mathrm{O}(34 \mathrm{~g}, 1.7 \mathrm{~mol})$ and $\mathrm{DCl} / \mathrm{D}_{2} \mathrm{O}(8 \mathrm{~g}, 20 \%)$ at 90 $100^{\circ} \mathrm{C}$ for $36 \mathrm{~h}$. After removal of the liquid in vacuo below $50^{\circ} \mathrm{C}$ the procedure was repeated twice, yielding sufficiently pure deuterochloride $(33 \mathrm{~g}, 91 \%)$. The mass spectrometric analysis $(15 \mathrm{eV})$ indicated $98.9 \% \mathrm{D}$ incorporation for the free base. [3,4,5$d_{3}$ ]bromobenzene ${ }^{32,} \uparrow$ was prepared in a similar manner to the procedure given by Leitch and co-workers ${ }^{33}$ by refluxing the anilinium chloride $(32.5 \mathrm{~g}, 0.15 \mathrm{~mol})$ with $\mathrm{D}_{3} \mathrm{PO}_{2} / \mathrm{D}_{2} \mathrm{O}(95 \mathrm{ml}, 50 \%)$ for $5 \mathrm{~min}$ under $\mathrm{N}_{2}$ in a pre-deuterated bulb. After cooling to $-15^{\circ} \mathrm{C}$ dried $\left(\mathrm{P}_{2} \mathrm{O}_{5}\right.$ in vacuo $) \mathrm{NaNO}_{2}(11.5 \mathrm{~g}, 0.17 \mathrm{~mol})$ was added with stirring in very small portions, keeping the reaction temperature below $-10^{\circ} \mathrm{C}$. After further stirring for $3 \mathrm{~h}$, the mixture was poured on ice and worked up. Distillation using a short column (b.p. $90^{\circ} \mathrm{C} / 90$ Torr) yielded the product $(107 \mathrm{~g}, 44 \%)$ with a $\mathrm{D}$ incorporation of $98.7 \%\left(96.7 \% d_{3}, 2.9 \% d_{2}, 0.3 \% d_{1}\right)$.

A solution of the Grignard compound (c. $15 \mathrm{mmol}$ ) of $\left[3,4,5-d_{3}\right]$ bromobenzene in ether $(c .5 .5 \mathrm{ml})$ and dry tetrahydrofuran $(20 \mathrm{ml})$ was cooled to $-15^{\circ} \mathrm{C}$ under $\mathrm{N}_{2}$. A solution of $\mathrm{Li}_{2} \mathrm{CuCl}_{4}$ in dry THF $(0.1 \mathrm{~m}, 1 \mathrm{ml})$ was added with stirring. (The latter solution was obtained from anhydrous $\mathrm{CuCl}_{2}, \mathrm{LiCl}$ and THF.) According to the method of Schlosser and Fouquet, ${ }^{34} 3$ phenylpropyl- $p$-toluenesulfonate $\quad(2.9 \mathrm{~g}, 10 \mathrm{mmol})$ prepared in the usual manner was added in portions and stirring continued for $24 \mathrm{~h}$ while warming to room temperature. After hydrolysis with $\mathrm{H}_{2} \mathrm{SO}_{4}$ $(2 \mathrm{~N})$, the mixture was worked up and distilled using a short Vigreux column. The fraction $(1.6 \mathrm{~g})$ boiling between 115 and $148^{\circ} \mathrm{C} / 12$ Torr was collected and redistilled to remove diphenyl and 1-bromo-3phenylpropane (as shown by mass spectrometry). The last fraction was bromine-free $\mathbf{1 b}$ (c. $0.6 \mathrm{~g}, 22 \%$ ), contaminated by less than $5 \%$ diphenyl.

1,3-Diphenyl-[1,1,2,2-d $\left.d_{4}\right]$ propane (1c). 1,3-Diphenylpropan-1-one $(2.6 \mathrm{~g}, 12.4 \mathrm{mmol})$ was stirred vigorously with $\mathrm{DCl} / \mathrm{D}_{2} \mathrm{O}(20 \mathrm{ml}, 10 \%)$ in a wellstoppered bulb at $70-80^{\circ} \mathrm{C}$ overnight, according to the procedure of Seibl and Gäumann. ${ }^{35}$ After extraction with dry ether $(4 \times 5 \mathrm{ml})$ and drying over $\mathrm{CaCl}_{2}$ the ether was removed. This procedure was repeated twice, yielding 1,3-diphenyl-[2,2- $\left.d_{2}\right]$ propan-2-one $(1.8 \mathrm{~g}, 69 \%)$ with $97 \% \mathrm{D}$ incorporation $(15 \mathrm{eV}: 94 \%$ $\left.d_{2}, 5 \% d_{1}, 1 \% d_{0}\right)$. Amalgamated zinc (4.2 g) [from fine-cut zinc sheet $(4.4 \mathrm{~g}), \mathrm{HgCl}_{2}(0.25 \mathrm{~g})$, conc. $\mathrm{DCl}$ $(0.3 \mathrm{ml})$ and $\left.\mathrm{D}_{2} \mathrm{O}(5 \mathrm{ml})\right], \mathrm{DCl} / \mathrm{D}_{2} \mathrm{O}(11 \mathrm{ml}, 30 \%)$ and $d_{2}$-ketone $(1.80 \mathrm{~g}, 8.5 \mathrm{mmol})$ were introduced quickly into a pre-deuterated bulb and heated under reflux for $24 \mathrm{~h}$ with additional vigorous stirring. During the first $8 \mathrm{~h}$ conc. $\mathrm{DCl}(0.5 \mathrm{ml})$ was added each $\mathrm{h}$. After extraction with ether, drying $\left(\mathrm{CaCl}_{2}\right)$ and removal of the ether the product was distilled, yielding 1c, $(1.22 \mathrm{~g}$, $72 \%$ ), b.p. ${ }_{11} 156-157^{\circ} \mathrm{C}$, which contained $10-15 \%$ of the corresponding propene $(\mathrm{m} / \mathrm{e} 196,100 \%$ and

$\dagger\left[3,4,5-d_{3}\right]$ Bromobenzene was prepared catalytically with relatively low specificity. 
$m / e 195,70 \%$ ). This contamination could be largely removed by stirring a solution of the product in petroleum ether $(4 \mathrm{ml})$ with conc. $\mathrm{H}_{2} \mathrm{SO}_{4}(5 \mathrm{ml})$ for $30 \mathrm{~min}$ at room temperature. Further purification of the product from $c .6$ down to 1 or $2 \%$ propene was achieved by PGLC (vide supra).

${ }^{1} \mathrm{H} \quad \mathrm{NMR} \quad\left(\mathrm{CCl}_{4}\right): \tau=7.33 \quad\left(\mathrm{~s}, 3-\mathrm{CH}_{2}\right), \quad 2.77$ $\left(\mathrm{mc}, \mathrm{C}_{6} \mathrm{H}_{5}\right) ; 1: 5$.

1-Phenyl-3-[2,6- $\left.d_{2}\right]$ phenylpropane (1d). Freshly distilled 2,6-dichlorobenzaldehyde $(72.2 \mathrm{~g}, 0.41 \mathrm{~mol})$ and acetophenone $(49.5 \mathrm{~g}, 0.41 \mathrm{~mol})$ were condensed in the usual manner to give 1-(2,6-dichlorophenyl)-3phenylprop-1-en-3-one, $(104 \mathrm{~g}, 92 \%)$ m.p. $83^{\circ} \mathrm{C}$ from EtOH. (Found C, 84.82; H, 3,72; Cl, 25.57. $\mathrm{C}_{15} \mathrm{H}_{10} \mathrm{Cl}_{2} \mathrm{O}$ requires $\mathrm{C}, 65.01 ; \mathrm{H}, 3.64 ; \mathrm{Cl}, 25,58 \%$.) The dichlorochalcone $(55.4 \mathrm{~g}, 0.20 \mathrm{~mol})$ in anhydrous ether $(700 \mathrm{ml})$ was added in the usual manner to $\mathrm{LiAlH}_{4}(4.6 \mathrm{~g}, 0.12 \mathrm{~mol})$ in ether $(200 \mathrm{ml})$. After stirring for $24 \mathrm{~h}$ the mixture containing the corresponding saturated ketone was worked up without acidification. The product mixture was refluxed with additional $\mathrm{LiAlH}_{4}(4.2 \mathrm{~g})$ in ether $(200 \mathrm{ml})$ for $6 \mathrm{~h}$, and gave a single product, 1-(2,6-dichlorophenyl)-3phenylpropan-3-ol $\left(46.6 \mathrm{~g}, 83 \%\right.$ ), m.p. $83-84^{\circ} \mathrm{C}$ from MeOH. (Found C, 63.99; H, 5.22; Cl, 25.85. $\mathrm{C}_{15} \mathrm{H}_{14} \mathrm{Cl}_{2} \mathrm{O}$ requires $\mathrm{C}, 64.07 ; \mathrm{H}, 5.02 ; \mathrm{Cl}, 25.22 \%$.) After Brewster and co-workers, ${ }^{36}$ the carbinol $(58 \mathrm{~g}$, $0.21 \mathrm{~mol}$ ) was added under $\mathrm{N}_{2}$ to a stirred, filtered solution of $\mathrm{LiAlH}_{4}(10.9 \mathrm{~g}, 0.29 \mathrm{~mol})$ and $\mathrm{AlCl}_{3}(77 \mathrm{~g}$, $0.58 \mathrm{~mol})$ in anhydrous ether $(210 \mathrm{ml}),{ }^{36}$ while keeping the reaction mixture at $0^{\circ} \mathrm{C}$. Stirring was continued for $50 \mathrm{~h}$ at room temperature. After pouring on crushed ice $(700 \mathrm{ml})$, the mixture was worked up by extracting with ether, drying over $\mathrm{K}_{2} \mathrm{CO}_{3}$ and distillation of the product using a Vigreux column giving 1-(2,6dichlorophenyl)-3-phenylpropane (contaminated by $c$. $10 \%$ of the corresponding propene, $m / e$ 262/264/266, and the monochloropropane, m/e 230/232), b.p. $136-138^{\circ} \mathrm{C} / 0.15$ Torr, yielding the pure product (46 g, 84\%). Found: C, 67.89: $\mathrm{H}, 5.32 ; \mathrm{Cl}, 26.91$ $\mathrm{C}_{15} \mathrm{H}_{14} \mathrm{Cl}_{2}$ requires $\mathrm{C}, 67.94 ; \mathrm{H}, 5.32 ; \mathrm{Cl}, 26.74 \%$.) In analogy to a procedure of Beynon and co-workers, ${ }^{37}$ $\mathrm{Mg}$ turnings $(3.67 \mathrm{~g})$ in anhydrous tetrahydrofural $(12.5 \mathrm{ml})$ were treated with 1,2-dibromoethane $(0.2 \mathrm{ml})$. After the reaction had started, the (contaminated) dichloro compound $(40 \mathrm{~g}, 0.15 \mathrm{~mol})$ in THF $(45 \mathrm{ml})$ was added slowly, followed by more THF $(40 \mathrm{ml})$. After refluxing for $18 \mathrm{~h}$ all the $\mathrm{Mg}$ was resolved. After cooling to room temperature, $\mathrm{D}_{2} \mathrm{O}(10 \mathrm{ml})$ was added with stirring. After further stirring for $3 \mathrm{~h}$ the hydroxide was treated with $20 \% \mathrm{HCl}(100 \mathrm{ml})$. After extraction with ether, washing of the combined organic layers with conc. $\mathrm{NaHCO}_{3}$ and water, the ether was dried over $\mathrm{K}_{2} \mathrm{CO}_{3}$ and evaporated. Distillation yielded two main fractions: b.p. 89$91^{\circ} \mathrm{C} / 0.2$ Torr $(2.5 \mathrm{~g})$ and b.p. $99-100^{\circ} \mathrm{C} / 0.2$ Torr $(20.5 \mathrm{~g}, 59 \%)$. The lower boiling fraction consisted mainly of 1-[ $\left.d_{1}\right]$ phenyl-3-phenylpropane $(\mathrm{m} / \mathrm{e} 197)$. The major fraction contained approximately $90 \%$ of $1-\left(2-\left[d_{1}\right]-6\right.$-chlorophenyl)-3-phenylpropane and $10 \%$ of the former compound, but no chlorosubstituted propene (vide supra). The $\mathrm{D}$ content of the latter compound was $91 \% d_{1}, 9 \% d_{0}$, as shown by mass spectrometry. A Grignard solution was prepared in the abovementioned manner from $\mathrm{Mg}$ turnings $(1.0 \mathrm{~g}$, $41 \mathrm{mmol})$ and the monochloro compound $(9.5 \mathrm{~g}$ $<41 \mathrm{mmol}$ ) added in $1 \mathrm{~h}$ in THF (i.e. $4+14 \mathrm{ml}$ ). After refluxing for $20 \mathrm{~h}$ the mixture was cooled, hydrolysed with $\mathrm{D}_{2} \mathrm{O}$ and worked up. Distillation using a Vigreux column yielded 1d $(5.1 \mathrm{~g}, 63 \%)$, b.p. 154$155^{\circ} \mathrm{C} / 16$ Torr, containing less than $1 \%$ of $1,3-$ diphenylpropene- $d_{1}$ (by mass spectrometry).

${ }^{1} \mathrm{H}$ NMR $\left(\mathrm{CCl}_{4}\right): \tau=8.0\left(\mathrm{~m}, 2-\mathrm{CH}_{2}\right), 7.33(\mathrm{t}, 1-$ and 3- $\left.\mathrm{CH}_{2}\right), 2.80\left(\mathrm{mc}, \mathrm{C}_{6} \mathrm{H}_{5}\right.$ and $\left.\mathrm{C}_{6} \mathrm{H}_{3} \mathrm{D}_{2}\right), 1: 2: 4$.

The site-specificity of the $d_{2}$ labelling in $1 \mathrm{~d}$ has been proved by applying the well-known ${ }^{38}$ exchange between the carboxylic and the ortho hydrogens in the molecular ions of benzoic acid before loss of $\mathrm{OH}^{\circ}:$ A sample of $1 d$ was oxidized by $\mathrm{KMnO}_{4} / \mathrm{Na}_{2} \mathrm{CO}_{3}$ to a mixture of $\mathrm{C}_{6} \mathrm{H}_{5} \mathrm{CO}_{2} \mathrm{H}, \quad \mathrm{C}_{6} \mathrm{H}_{4} \mathrm{DCO}_{2} \mathrm{H}$ and $\mathrm{C}_{6} \mathrm{H}_{3} \mathrm{D}_{2} \mathrm{CO}_{2} \mathrm{H}$ in the ratio of $53.8: 9.6: 36.7$. (During oxidation the degree of labelling decreased from $1.83 \mathrm{D} \mathrm{mol}^{-1}$ to $1.66 \mathrm{D} \mathrm{mol}^{-1}$.) The ion source of the 311 A mass spectrometer was calibrated with commercially available $\left[d_{5}\right]$ benzoic acid (the ratio of loss of $\mathrm{OH}^{\circ}$ and loss of $\mathrm{OD}^{\circ}$ was $79.7: 20.3$ after corrections for incomplete $\mathrm{D}$ content and loss of $\mathrm{HDO}$ and $\mathrm{D}_{2} \mathrm{O}$ ). Using this value the relative abundances expected for the $[\mathrm{M}-\mathrm{O}(\mathrm{H}, \mathrm{D})]^{+}$partial spectrum of the mixture were calculated and compared with the experimental abundances. Very good agreement was found: $[104]:[105]:[106]:[107]$ were observed to be in the ratio $0.6: 54.3: 15.8: 29.3$ and calculated to be $0: 54.8: 16.0: 29.3$.

Thus, using the procedure described for ortho- $d_{2}$ labelling, migration of the $\mathrm{Cl}$ substituents does not occur and the deuterium was introduced specifically at the ortho positions of $1 d$.

1-Phenyl-3-[ $\boldsymbol{d}_{5}$ ]phenylpropane (1e). Freshly distilled 3-phenylpropanal $(2.7 \mathrm{~g}, 20 \mathrm{mmol})$ was reacted in the conventional manner with $\left[d_{5}\right]$ phenylmagnesiumbromide made from $\left[d_{5}\right]$ bromobenzene $(4.05 \mathrm{~g})$ and $\mathrm{Mg}$ turnings $(0.61 \mathrm{~g}, 25 \mathrm{mmol})$. The carbinol was oxidized without purification with activated $\mathrm{MnO}_{2}(22 \mathrm{~g}$, $0.25 \mathrm{~mol}$, Merck) in ether $(150 \mathrm{ml})$ during $24 \mathrm{~h}$ to 1 phenyl-3-[ $\left.d_{5}\right]$ phenylpropan-3-one $(94 \%$, based on the starting aldehyde, after recrystallization from EtOH), m.p. $70-71^{\circ} \mathrm{C}$. D content $>99 \% d_{5}(15 \mathrm{eV})$.

Analogous to the method for 1c, 1e was prepared by Clemmensen reduction of the above ketone $(1.2 \mathrm{~g}$, $5.6 \mathrm{mmol})$ with $\mathrm{Zn} / \mathrm{Hg}(1.4 \mathrm{~g})$ and $\mathrm{HCl}(4.5+0.2+$ $0.2 \mathrm{ml}, 30 \%$ ). The reaction was stopped after $3 \mathrm{~h}$ in order to minimize the loss of label. Working up yielded $0.45 \mathrm{~g}$ of a product containing c. $15 \%$ labelled 1,3-diphenylpropene. It was purified by treatment with conc. $\mathrm{H}_{2} \mathrm{SO}_{4}$ /petroleum ether and PGLC (vide supra).

${ }^{1} \mathrm{H}$ NMR $\left(\mathrm{CCl}_{4}\right): \tau=8.0\left(\mathrm{~m}, 2-\mathrm{CH}_{2}\right), 7.36(\mathrm{t}, 1-$ and $\left.3-\mathrm{CH}_{2}\right), 2.82\left(\mathrm{mc}, \mathrm{C}_{6} \mathrm{H}_{5}\right), 2: 4: 5$.

1-Phenyl-3- $\left[d_{5}\right]$ phenyl- $\left[2,2,3,3-d_{4}\right]$ propane (1f). Similarly to the procedure given for 1c, 1-phenyl-3$\left[d_{5}\right]$ phenylpropan-3-one $(2.40 \mathrm{~g}, 11 \mathrm{mmol})$ was reacted three times with $\mathrm{DCl}$ to yield 1-phenyl-3$\left[d_{5}\right]$ phenyl-[2,2- $\left.d_{2}\right]$ propan-3-one $(1.62 \mathrm{~g}, 67 \%)$, the D content of which was $91 \% d_{7}, 7 \% d_{6} .2 \% d_{5}(15 \mathrm{eV})$. As for 1c (and 1e), this ketone $(1.50 \mathrm{~g}, 6.9 \mathrm{mmol})$ was reduced during $5 \mathrm{~h}$ heating under reflux to $1 \mathrm{f}(0.73 \mathrm{~g}$, $52 \%$ ), containing c. $4 \%$ labelled 1,3 -diphenylpropene. 
After further purification by PGLC, the contamination was decreased to $2 \%$.

${ }^{1} \mathrm{H}$ NMR : $\tau=7.34\left(\mathrm{~s}, 1-\mathrm{CH}_{2}\right), 2.80\left(\mathrm{mc}, \mathrm{C}_{6} \mathrm{H}_{5}\right), 2: 5$. 1-Phenyl-3- $\left[d_{5}\right]$ phenyl-[1,1,2,2- $\left.d_{4}\right]$ propane (1g). 1$\left[d_{5}\right]$ Phenyl-3-phenylprop-1-ene-3-one $\quad(6.4 \mathrm{~g}, \quad 30$ mmol), obtained in the usual manner from acetophenone and $\left[d_{5}\right]$ benzaldehyde, was hydrogenated in ethylacetate $(75 \mathrm{ml})$ over Adams catalyst $(50 \mathrm{mg})$ at room temperature. Absorption was stopped after $30 \mathrm{~min}$ after 1.05 equiv. of $\mathrm{H}_{2}$ were absorbed. Recrystallization from EtOH yielded 1-phenyl-3$\left[d_{5}\right]$ phenyl-1-propan-1-one $(4.8 \mathrm{~g}, 74 \%)$, m.p. $71^{\circ} \mathrm{C}$, showing no loss of label $\left(d_{5}>99 \%\right)$. Similarly to the procedure given for 1c, the above ketone $(4.6 \mathrm{~g}$,
$21 \mathrm{mmol})$ was converted to 1-phenyl-3-[ $\left.d_{5}\right]$ phenyl[2.2- $\left.d_{2}\right]$ propan-1-one $(4.0 \mathrm{~g}, 86 \%)$, consisting of $92 \%$ $d_{7}, 6 \% d_{6}$ and $2 \% d_{5}(15 \mathrm{eV})$. Similarly to $1 \mathrm{c}$, the $d_{7}$-ketone $(3.75 \mathrm{~g}, 17 \mathrm{mmol})$ was reduced during $5 \mathrm{~h}$ to $1 \mathrm{~g}(1.78 \mathrm{~g}, 50 \%)$, containing $c .4 \%$ of labelled $1,3-$ diphenylpropene (after PLGC 2\%).

${ }^{1} \mathrm{H}$ NMR : $\tau=7.38\left(\mathrm{~s}, 3-\mathrm{CH}_{2}\right), 2.82\left(\mathrm{mc} \mathrm{C}_{6} \mathrm{H}_{5}\right), 2: 5$.

\section{Acknowledgement}

The investigations were supported by the 'Forschungsprojekt 2142' der Universität Bielefeld.

\section{REFERENCES}

1. D. Kuck and H. F. Grützmacher, Org. Mass Spectrom. 13. 81 (1978).

2. American Petroleum Institute Research Project 44, Spectrum No. 1967.

3. D. A. Lightner, G. B. Quistad and E. Irwin, Appl. Spectrosc. 25, 253 (1971).

4. P. Brown, Org. Mass Spectrom. 3, 1175 (1970).

5. (a) D. H. Williams, R. S. Ward and R. G. Cooks, J. Chem. Soc. $B 522$ (1968); (b) U. Neuert, Doctoral Thesis, Hamburg (1975).

6. J.K. McLeod and C. Djerassi, Tetrahedron Lett. 2183 (1966).

7. (a) H. M. Grubb and $S$. Meyerson in Mass Spectrometry of Organic lons', ed. by F. W. McLafferty, Chapt 10. Academic Press, New York (1963); (b) J. T. Bursey and D. G. I. Kingston, Chem. Rev. 73, 191 (1973).

8. D. Kuck and H. F. Grützmacher, in preparation.

9. M. A. Baldwin, F. W. McLafferty and D. M. Jerina, J. Am. Chem. Soc. 97, 6169 (1975).

10. (a) M. L. Gross and F. L. DeRoos, J. Am. Chem. Soc. 98 , 7128 (1976); (b) M. L. Gross, E. Chiu, D. Pokorny and F. L. DeRoos, Org. Mass Spectrom. 12, 55 (1977).

11. D. Kuck, Doctoral Thesis, Bielefeld (1976).

12. (a) H. C. Brown and J. D. Brady, J. Am. Chem. Soc. 74, 3570 (1952); (b) H.-H. Perkampus and E. Baumgarten, Angew. Chem. 76, 965 (1964); (c) G. A. Olah, Angew. Chem. 85, 183 (1973); (d) G. A. Olah, R. H. Schlosberg, R. D. Porter, Y. K. Mo, D. P. Kelly and G. D. Mateescu, J. Am. Chem. Soc. 94, 2034 (1972); (e) G. A. Olah, A. E. Pavlath and J. A. Olah, J. Am. Chem. Soc. 80, 6540 (1958); (f) G. A. Olah and S. J. Kuhn, J. Am. Chem. Soc. 80, 6541 (1958); (g) D. Farcasiu, M. T. Melchior and J. Craine, Angew. Chem. 89, 323 (1977).

13. W. J. Hehre, R. T. Mclver Jr, J. A. Pople and P. v. R. Schleyer, J. Am. Chem. Soc. 96, 7162 (1974); (b) B. S. Freiser, R. L. Woodin and J. L. Beauchamp, J. Am. Chem. Soc. 97, 6893 (1975); (c) J. M. McKelvey, S. Alexandratos, A. Streitwieser Jr, J.-L. M. Abboud and W. J. Hehre, J. Am. Chem. Soc. 98, 244 (1976); (d) J. L. Devlin III, J. F. Wolf, R. W. Taft and W. J. Hehre, J. Am. Chem. Soc. 98, 1990 (1976); (e) Y. K. Lau and P. Kebarle, J. Am. Chem. Soc. 98, 7452 (1976); (f) D. P. Martinsen and S. E. Buttrill Jr, Org. Mass Spectrom. 11, 762 (1976); (g) W. J. Hehre and J. A. Pople, J. Am. Chem. Soc. 94, 6901 (1972).

14. A. M. Duffield, R. Beugelmans, H. Budzikiewicz, D. A. Lightner, D. H. Williams and C. Djerassi, J. Am. Chem. Soc. 87, 805 (1965).

15. A. N. H. Yeo and D. H. Williams, J. Am. Chem. Soc. 91, 3582 (1969).

16. A. F. Gerrard and C. Djerassi, J. Am. Chem. Soc. 91, 6808 (1969).

17. K. U. Ingold, in 'Free Radicals', Vol. 1, ed. by J. K. Kochi, Wiley, New York (1973) and references cited therein.

18. M. A. Winnik, Org. Mass Spectrom. 9, 920 (1974).

19. (a) J. L. Franklin, J. G. Dillard, H. M. Rosenstock, J. T. Herron, K. Draxl and F. H. Field, Yonization Potentials, Appearance Potentials and Heats of Formation of Gaseous
Positive lons', US Department of Commerce, NSRDS-NBS 26, Washington, D.C. (1969); (b) D. G. L. James and R. D. Suart, Chem. Commun. 484 (1966); (c) J. B. Farmer, F. P. Lossing, D. G. H. Marsden and C. A. McDowell, J. Chem. Phys. 24, 52 (1956).

20. J. A. Kerr, Chem. Rev. 66, 465 (1966).

21. D. Kuck, unpublished results.

22. D. H. Williams and R. D. Bowen Org. Mass Spectrom. 11, 223 (1976).

23. (a) J. Occolowitz, cited in Ref. 28 as a private communication; (b) M. J. S. Dewar and D. Landman, J. Am. Chem. Soc. 99, 2446 (1977).

24. C. E. Melton, in 'Mass Spectrometry of Organic lons', ed. by F. W. McLafferty, Chapt. 2. Academic Press, New York (1963).

25. K. Levsen, F. W. McLafferty and D. M. Jerina, J. Am. Chem. Soc. 95, $6332(1973)$

26. M. M. Bursey, M. K. Hoffman and S. A. Benezra, Chem. Commun. 1417 (1971).

27. R. Nicoletti and D. A. Lightner, J. Am. Chem. Soc. 90, 2997 (1968).

28. H. Budzikiewicz, C. Djerassi and D. H. Williams, 'Mass Spectrometry of Organic Compounds', p. 82. Holden-Day, San Francisco (1967).

29. (a) P. J. Derrick and A. L. Burlingame, J. Am. Chem. Soc. 96, 4909 (1974); (b) P. J. Derrick, A. M. Falick and A. L. Burlingame, J. Am. Chem. Soc. 94,6794 (1972).

30. (a) J. March, Advanced Organic Chemistry: Reactions, Mechanisms and Structure, pp. 376-382. McGraw-Hill, New York (1968); (b) G. A. Olah, Acc. Chem. Res. 4, 240 (1971); (c) D. V. Banthorpe, Chem. Rev. 70, 295 (1970).

31. H. Schmid and P. Karrer, Helv. Chim. Acta 32, 1371 (1949).

32. J. L. Garnett and R. J. Hodges, Chem. Commun. 1001 (1967).

33. R. N. Renaud, D. Kovachic and L. C. Leitch, Can. J. Chem. 39, 21 (1961).

34. (a) G. Fouquet and M. Schlosser, Angew. Chem. 86, 50 (1974); (b) M. Schlosser, Angew. Chem. 86, 751 (1974).

35. (a) J. Seibl and T. Gäumann, Helv. Chim. Acta 46, 2857 (1968); (b) A. F. Thomas, Deuterium Labeling in Organic Chemistry, p. 171. Appleton-Century-Crofts, New York (1971).

36. J. H. Brewster, H. O. Bayer and S. F. Osman, J. Org. Chem. 29, 110 (1964).

37. J. H. Beynon, J. E. Corn, W. E. Baitinger, J. W. Amy and R. A. Benkeser, Org. Mass Spectrom. 3, 191 (1970).

38. (a) J. H. Beynon, B. E. Job and A. E. Williams, Z. Naturforsch. Teil. A, 20, 885 (1965); (b) S. Meyerson and J. L. Corbin, J. Am. Chem. Soc. 87, 3045 (1965); (c) I. Howe and F. W. McLafferty, J. Am. Chem. Soc. 92, 3797 (1970).

Received 25 July 1977; accepted 15 September 1977

(C) Heyden \& Son Ltd, 1978 